\title{
Toxoplasma gondii subverts the host ESCRT machinery for parasite uptake of host cytosolic
} proteins

Yolanda Rivera-Cuevas ${ }^{1}$, Joshua Mayoral², Manlio Di Cristina ${ }^{3}$, Anna-Lisa E. Lawrence ${ }^{1}$, Einar B. Olafsson $^{1}$, Dishari Thornhill ${ }^{1}$, Benjamin S. Waldman ${ }^{4,5, \#}$, Akira Ono ${ }^{1}$, Jonathan Sexton ${ }^{6}$, Sebastian Lourido $^{4,5}$, Louis M. Weiss ${ }^{2,7}$, Vern B. Carruthers ${ }^{1,{ }^{*}}$

Author affiliations:

${ }^{1}$ Department of Microbiology and Immunology, University of Michigan Medical School, Ann Arbor, MI, USA 48109

${ }^{2}$ Department of Pathology, Albert Einstein College of Medicine, Bronx, NY, USA

${ }^{3}$ Department of Chemistry, Biology and Biotechnology, University of Perugia, Perugia, Italy

${ }^{4}$ Whitehead Institute for Biomedical Research, Cambridge, MA, USA 02139

${ }^{5}$ Department of Biology, Massachusetts Institute of Technology, Cambridge, MA, USA 02139

${ }^{6}$ Department of Medicinal Chemistry, College of Pharmacy, Ann Arbor, MI, USA 48109

${ }^{7}$ Department of Medicine, Albert Einstein College of Medicine, Bronx, NY, USA

\#Current affiliation: Department of Microbiology and Immunology, Stanford University School of Medicine, Stanford, CA USA 94305

*Correspondence: vcarruth@umich.edu

Running title: T. gondii exploitation of host ESCRT

Keywords: parasite, endocytosis, ingestion, infection 


\section{Abstract}

Toxoplasma gondii is a master manipulator capable of effectively siphoning the resources from the host cell for its intracellular subsistence. However, the molecular underpinnings of how the parasite gains resources from its host remain largely unknown. Residing within a non-fusogenic parasitophorous vacuole, the parasite must acquire resources across the limiting membrane of its replicative niche, which is decorated with parasite proteins including those secreted from dense granules. We discovered a role for the Endosomal Sorting Complex Required for Transport (ESCRT) machinery in host cytosolic protein uptake by $T$. gondii by disrupting host ESCRT function. We identified the transmembrane dense granule protein TgGRA14, which contains motifs homologous to the late domain motifs of HIV-1 Gag, as a candidate for the recruitment of the host ESCRT machinery to the PV membrane. Using an HIV virus-like particle (VLP) release assay, we found that the motif-containing portion of TgGRA14 is sufficient to substitute for HIV Gag late domain to mediate ESCRT-dependent VLP budding. We also show that TgGRA14 is proximal to and interacts with host ESCRT components and other dense granule proteins during infection. Furthermore, analysis of GRA14-deficient parasites revealed a marked reduction in ingestion of a host cytosolic protein compared to WT parasites. Thus, we propose a model in which $T$. gondii recruits the host ESCRT machinery to the PV where it can interact with TgGRA14 for the internalization of host cytosolic proteins across the PVM. These findings provide new insight into how $T$. gondii accesses contents of the host cytosol by exploiting a key pathway for vesicular budding and membrane scission.

\section{Author summary}

Intracellular pathogens exploit their host to gain the resources necessary to sustain infection; however, precisely how the intracellular parasite Toxoplasma gondii acquires essential nutrients from its host remains poorly understood. Previous work showed that $T$. gondii is capable of internalizing host derived cytosolic proteins and delivering them to its lysosome-like compartment for degradation. However, the 
bioRxiv preprint doi: https://doi.org/10.1101/2021.07.21.453261; this version posted July 21, 2021. The copyright holder for this preprint (which was not certified by peer review) is the author/funder, who has granted bioRxiv a license to display the preprint in perpetuity. It is made available under aCC-BY-NC 4.0 International license.

mechanism by which the material is trafficked across the membrane delimiting the replicative vacuole in which the parasite resides remained unclear. Here, we report a role for the parasite effector protein TgGRA14 in the recruitment of the host ESCRT machinery for the uptake of host cytosolic proteins. Important human pathogens have developed strategies for exploiting the host ESCRT machinery for intracellular subsistence. Our study sheds lights on the strategy used by a eukaryotic pathogen in subverting the host ESCRT machinery for the internalization of resources from its host cells. 


\section{Introduction}

Intracellular pathogens have evolved diverse strategies that rely on the exploitation of host factors to ensure intracellular subsistence, replication, and immune evasion. The protozoan parasite Toxoplasma gondii is a successful intracellular pathogen that can infect a wide range of nucleated cells while residing in a classical non-fusogenic replicative vacuole that helps protect it from host intrinsic defenses. This replicative vacuole, known as the parasitophorous vacuole (PV), is remodeled by a subset of specialized secretory proteins called dense granules proteins (GRAs) ${ }^{1}$. Although this compartment also segregates the parasite from the nutrient-rich environment of the host cytosol, $T$. gondii has developed multiple mechanisms for acquiring the resources it needs to sustain infection ${ }^{2}$.

T. gondii is capable of internalizing host-derived cytosolic proteins ${ }^{3}$. Once endocytosed, the material is trafficked throughout the endolysosomal system of the parasite and delivered to its lysosomal vacuolar-like compartment (VAC) for degradation by the cysteine protease cathepsin $\mathrm{L}(\mathrm{TgCPL})^{4}$. However, the molecular mechanisms by which this material is trafficked across the PV membrane (PVM) and is further endocytosed by the parasite remained poorly understood.

Several parasite-host interactions involve the recruitment and exploitation of host factors ${ }^{5}$ and organelles to the $\mathrm{PVM}^{6-8}$. For example, $T$. gondii is known to exploit a subset of the host endosomal sorting complex required for transport (ESCRT) machinery during its invasion of host cells ${ }^{9}$. More recent work has shown that host ESCRT is also recruited to the PVM during parasite replication ${ }^{10}$. This latter recruitment likely occurs via a distinct mechanism since it involves many more components of the ESCRT machinery than that for cell invasion. ESCRT is involved in various cellular processes including formation of the multivesicular body (MVB), plasma membrane repair, cytokinesis, exosome release, and autophagy ${ }^{11,12}$. The machinery is composed of five complexes ESCRT-0, ESCRT-I, ESCRT-II, ESCRT-III, and the Vps4 complex, which sequentially interact with each other to bud vesicles away from the cytosol ${ }^{13}$. Although the localization of ESCRT components at the PV is consistent with a possible role in facilitating the budding of vesicles into the PV lumen, to date there are no reports of parasite proteins that interact with host ESCRT during parasite replication. 
A variety of important human pathogens have developed mechanisms for recruiting host cell ESCRT machinery to ensure an efficient infection and transmission. Intracellular pathogens that differ in pathogenesis, such as the human immunodeficiency virus $(\mathrm{HIV})^{14-18}$, dengue virus ${ }^{19}$, hepatitis $\mathrm{C}$ virus $(\mathrm{HCV})^{20,21}$, Ebola virus ${ }^{22,23}$, and Mycobacterium tuberculosis ${ }^{24,25}$ have all evolved mechanisms to interact with the host ESCRT machinery. However, the contribution of ESCRT machinery in the pathogenesis of an intracellular eukaryotic microorganism remains limited to the aforementioned role in T. gondii cell invasion.

Herein we show that disruption of the host ESCRT machinery impairs host cytosolic protein uptake in T. gondii. Furthermore, we identified TgGRA14, a PVM resident dense granule protein ${ }^{26}$ that possesses ESCRT recruitment motifs, as a host ESCRT-interacting protein. The ESCRT recruitment motifs encoded in TgGRA14 are exposed to the host cytosol and are capable of recruiting ESCRT in the context of HIV-1 virus-like particle release. Additionally, replicating TgGRA14-deficient parasites have a markedly lower percentage of internalized host cytosolic protein compared to wildtype, demonstrating that TgGRA14 contributes to ingestion. Nonetheless, recruitment of host ESCRT components to the PV is not completely dependent on TgGRA14 given that the recruitment of the accessory ESCRT protein ALIX is not affected by disruption of TgGRA14. Importantly, recruitment of TSG101 relies on TgGRA14, and specifically involved the PTAP motif encoded in TgGRA14.

Collectively, our data supports a model in which T. gondii uses TgGRA14 and likely other GRA proteins to usurp the host ESCRT machinery for the vesicular transport of host cytosolic proteins across the PVM.

\section{Results}

\section{Disruption of the host ESCRT machinery impairs uptake of host cytosolic proteins}

The ESCRT machinery is composed of five complexes (ESCRT-0 - ESCRT-III and VPS4) that subsequently interact with one another to form vesicles that bud away from the cytosol (Fig. 1A). At the last step, the AAA ATPases, VPS4A or VPS4B, hydrolyze ATP to disassemble the machinery at the 
membrane and facilitate scission ${ }^{27,28}$. Expression of a dominant negative form of VPS4A (VPS4A ${ }^{\mathrm{EQ}}$ ), which is unable to hydrolyze ATP ${ }^{29}$, results in the accumulation of the ESCRT-III component CHMP4A at endosomal structures due to failed scission events (Fig. 1B). These structures formed by the inability of VPS4A to disassemble the ESCRT machinery accumulate proximal to the parasite PV during infection (Fig. 1C). To determine whether T. gondii relies on the host ESCRT machinery during infection we analyzed replication following disruption of the host ESCRT machinery through the expression of VPS4A ${ }^{\mathrm{EQ}}$. Compared to cells expressing exogenous VPS4A-wildtype (VPS4A ${ }^{\mathrm{WT}}$ ), there was a moderate replication defect in parasites growing in cells expressing VPS4A ${ }^{\mathrm{EQ}}$ (Fig. 1D and Fig. 1E). To test if the host ESCRT machinery plays a role in the uptake of host cytosolic proteins by $T$. gondii, host cells were transfected with a cytosolic fluorescent reporter protein (Venus) in addition to either VPS4A ${ }^{W T}$ or VPS4A ${ }^{E Q}$. To visualize the accumulation of internalized material within the parasite's lysosome-like VAC, the transfected cells were infected with parasites lacking the major VAC protease $\operatorname{TgCPL}(\mathrm{R} \Delta c p)$. As expected, based on previous studies ${ }^{4}, \mathrm{R} \Delta c p /$ parasites are capable of internalizing host-derived Venus. Interestingly, we found that exogenous expression of VPS4A ${ }^{\mathrm{EQ}}$, but not VPS4A ${ }^{\mathrm{WT}}$, impaired $\mathrm{R} \Delta c p$ / accumulation of Venus in newly invaded (Fig. 1F) and replicating (Fig. 1G) parasites. These findings suggest that disruption of host ESCRT limits parasite replication and uptake of host cytosolic proteins.

\section{Bioinformatic search identified TgGRA14 as a candidate ESCRT-interacting protein}

Enveloped viruses including HIV and HCV can exploit the host ESCRT machinery for viral budding ${ }^{30}$. In the case of HIV, the host ESCRT machinery is recruited to the site of viral budding by the Gag protein through the late-domain motifs, such as PTAP and $\mathrm{YPX}_{(\mathrm{n})} \mathrm{L}$, which are capable of interacting with the ESCRT-I component Tumor suppressor gene 101 (TSG101) and the ESCRT accessory Programmed cell death 6-interacting protein (PDCD6IP/ALIX, ALIX hereafter), respectively ${ }^{15,31}$. To identify T. gondii effector proteins as candidates for the recruitment of the host ESCRT machinery, we performed a bioinformatic search using the vEuPathDB Toxoplasma Informatics Resources Database (ToxoDB). 
The first step in our research strategy consisted of a motif search for proteins within the $T$. gondii genome encoding the late domain motif $\mathrm{P}(\mathrm{S} / \mathrm{T}) \mathrm{AP}$. As a second step we looked for proteins that also encode a signal peptide to center our search on secreted proteins. Through this search strategy we identified 33 secretory proteins with a putative P(S/T)AP late domain motif (Table S1). The identified candidates included the rhoptry neck protein RON5, which has been shown to interact with the host TSG101 ESCRT-I protein during cell invasion ${ }^{32}$. However, RON5 is only secreted during invasion and is not present at the host-parasite interface during parasite replication. We considered GRA proteins as better candidates since they are secreted continuously during parasite replication ${ }^{33}$. Three of the 33 genes identified were predicted to be dense granule proteins (GRAs) based on data from a recent extensive subcellular proteomics study ${ }^{34}$ (Table S1).

Among the 33 identified candidates, we prioritized the PV transmembrane protein TgGRA14 because previous work showed that its $\mathrm{C}$-terminus, which encodes a PTAP motif for putative binding to TSG101, is exposed to the host cytosol ${ }^{26}$. Just downstream of the PTAP motif we also identified a $\operatorname{YPX}_{(n)} \mathrm{L}$ motif for the potential recruitment of ALIX (Fig. 2A). Since HIV Gag uses both a PTAP and a $\mathrm{YPX}_{(\mathrm{n})} \mathrm{L}$ motif to direct virus budding ${ }^{17}$, we predicted that like HIV Gag, TgGRA14 would associate with ESCRT components at the PVM to promote vesicle formation (Fig. 2B). If so, we further reasoned that if the C-terminal domain of TgGRA14 would functionally interact with ESCRT and could be functionally equivalent to the late-domain containing p6 domain of HIV Gag. To test this, we transfected cells with constructs expressing HIV-1 Gag, HIV-1 Gag lacking the p6 late domain (Gag $\Delta p 6)$ and HIV Gag with the p6 domain substituted with the TgGRA14 C-terminal domain (Fig. 2C). As expected, expression of HIV -1 Gag sustained the release of virus-like particles (VLPS) in an ESCRT dependent manner, and deletion of the p6 domain diminished VLP production, with residual release being independent of ESCRT (Fig. 2D). Interestingly, substitution of the late-domain motif portion of TgGRA14 for the HIV-1 p6 domain allowed VLP production that equaled that of native HIV-1 Gag, with release being similarly dependent on ESCRT. Thus, when coupled with HIV-1 Gag, the C-terminal region of TgGRA14 encoding late domain motifs can function for exploitation of host ESCRT for the release of HIV-1 VLPS. 


\section{TgGRA14 is proximal to ALIX and TSG101}

Having established that TgGRA14 can subvert ESCRT in the context of viral budding we next turned our attention to determining if TgGRA14 is linked to ESCRT during T. gondii infection of host cells.

First, we stained for ALIX in HeLa cells expressing endogenously tagged GFP-TSG10135 to determine if these ESCRT proteins are recruited to the PV in parasites overexpressing GRA14 C-terminally tagged with $\mathrm{HA}^{26}$ (R:GRA14OE). Analysis by structured illumination microscopy (SIM) showed that ALIX is recruited to the PV (Fig. 3A), consistent with what has been observed by Cygan, A. M., et allo. This analysis further revealed that GFP-TSG101 is also abundantly recruited to the PV where it and ALIX both colocalize with TgGRA14-HA (Fig. 3A). To further analyze the juxtaposition of ALIX and GFPTSG101 with TgGRA14, we performed a proximity ligation assay (PLA) for which a positive reaction indicates that two proteins are within $40 \mathrm{~nm}$ of one another. This approach has been used previously to study the interactions of ESCRT components in Kaposi's Sarcoma-Associated Herpesvirus (KSHV) infected cells ${ }^{36,37}$. We used the R:GRA14 OE parasite strain and probed with anti-HA to detect TgGRA14. Whereas no signal was observed in untagged parasites (WT, RH parasites), we consistently detected a reaction between ALIX and TgGRA14-HA in tagged parasites (Fig. 3B). As an additional test of specificity, we did not see a reaction between TgGRA14-HA and MAPK7, a host kinase localized throughout the cytosol. We also observed positive reactions between TgGRA14-HA and GFP-TSG101 in infected endotagged GFP-TSG101 HeLa cells that were absent in infected untagged HeLa cells (Fig. 3C). Together these findings suggest that ALIX and TSG101 are intimately associated with TgGRA14 in infected cells (i.e within $40 \mathrm{~nm}$ of each other).

\section{TgGRA14 influences PV recruitment of GFP-TSG101 but not ALIX}

To determine if recruitment of host ESCRT components to the PV is dependent on TgGRA14 we infected GFP-TSG101 HeLa cells with WT or RAgra14 parasites and probed for host ALIX. After comparing the recruitment of both ESCRT components, we observed defects in the recruitment of 
GFP-TSG101 but not ALIX in TgGRA14-deficient parasites (Fig. 4A). Using a spinning disk confocal high content imaging instrument we quantified the abundance of GFP-TSG101 and ALIX in the PV between WT, RAgra14 and R:GRA14 $\mathrm{OE}$ to determine if overexpression of TgGRA14 could also affect their recruitment. Quantification of confocal images revealed that recruitment of ALIX to the PVM is not affected by overexpression or loss of TgGRA14 (Fig. S1 and 4B). In contrast, overexpression of TgGRA14 increased recruitment of GFP-TSG101 and ablation of TgGRA14 significantly reduced GFPTSG101 recruitment to the PV (Fig. S1 and 4D). Whether ALIX recruitment is entirely independent of TgGRA14 or through a redundant mechanism in the absence of TgGRA14 remains to be elucidated. Regardless, these findings suggest that TgGRA14 contributes to the PV recruitment of TSG101.

\section{TgGRA14 associates with components of host ESCRT}

To determine if TgGRA14 physically associates with other ESCRT components, we analyzed interacting proteins by immunoprecipitation (IP) and liquid chromatography tandem mass spectrometry (LC-MS/MS). To avoid potential artifacts due to overexpression, we generated a strain with GRA14 endogenously epitope-tagged at the C-terminus with HA in the genetically tractable ME49 $\Delta$ ku80 background using CRISPR/Cas9 gene editing (Fig. S2). Protein lysates were harvested either from infected human fibroblast cultures (either under tachyzoite (Tz-HFF) or bradyzoite growth conditions (Bz-HFF)) or infected mouse primary cortical neuron cultures (Tz-Neuron). Anti-HA coated magnetic beads were used to enrich for GRA14 protein from lysates, and eluates were harvested for LC-MS/MS. As a control for IP experiments, non-tagged ME49 $\Delta k u 80$ parasites were used and processed in parallel to cell cultures infected with GRA14-tagged parasites. Notably, results from the IP-MS/MS analysis of tachyzoite infected human fibroblast (Tz-HFF) cultures revealed that most of the significantly enriched host proteins were related to the ESCRT machinery (Fig. 5A) (Table S2A). Several of these interactions were verified by IP/immunoblot (Fig. 5B). As predicted, both TSG101 and ALIX immunoprecipitated with TgGRA14, along with most components of the ESCRT-I complex, several components of the ESCRT-III complex and the ESCRT-adaptor protein Programed cell death 6 
(PDCD6/ALG-2, ALG-2 hereafter) ${ }^{38,39}$. Interestingly, the ALG-2 interacting protein Peflin (PEF1) ${ }^{40}$ also immunoprecipitated with TgGRA14; however, a role for PEF1 in ESCRT mediated vesicle formation has not been reported. The IP analysis also identified GRA14 interactions with several other parasite proteins including soluble (TgGRA1, TgMAG1) and transmembrane (TgGRA8, TgGRA15 and TgGRA4) dense granule proteins (Fig. 5C) (Table S2B), which were confirmed by IP/immunoblot (Fig. 5D). Altogether, this data supports a working model in which TgGRA14 interacts with host ESCRT machinery at the PVM where it can potentially trigger vesicle formation to enclose host cytosolic proteins.

\section{TgGRA14 is important for ingestion of host cytosolic proteins late in infection}

To further test the model, we next assessed the role of TgGRA14 in the uptake of host cytosolic proteins using type I RH parasites lacking TgGRA14 (RAgra14). Parasites were treated with the CPL inhibitor LHVS prior to infection of mCherry inducible HeLa cells and harvested at 4 hours post-infection (hpi) (Fig. S3A). Since TgGRA14-deficient parasites showed normal ingestion at this time point (Fig. S3B), we decided to begin treating the parasites with LHVS at 4 hpi to determine if TgGRA14 is necessary for the uptake of host cytosolic proteins later in infection (Fig. 6A). Quantification of ingestion at $24 \mathrm{hpi}$ in this scheme revealed a significant reduction in uptake of host cytosolic proteins in TgGRA14-deficient parasites (Fig. 6B). To assess whether this was conserved between strains, we generated GRA14-deficient parasites in the type II ME49 $\Delta$ ku80 background (M $\Delta$ gra14) (Fig. S4). Like $\mathrm{R} \Delta$ gra14, we observed a significant reduction in the percentage of mCherry-containing parasites in the M $\Delta$ gra14 at 24 hpi (Fig. 6C). From these data we conclude that TgGRA14 is important for the uptake of host cytosolic proteins late during the later stages of intracellular infection.

\section{Late domain motifs encoded in TgGRA14 are important for VLP release but not for ingestion}

Although HIV Gag encodes several late domain motifs that can interact with multiple ESCRT components to initiate assembly of the machinery, recruitment of the ESCRT machinery at the site of 
viral budding through its interaction with TSG101 appears to be the most critical ${ }^{41}$. Given that TgGRA14 similarly encodes several late domain motifs, we wanted to identify the main late domain motif facilitating the recruitment of the host ESCRT machinery. To that end, we made alanine substitutions TgGRA14 PTAP and YPX $(n) L$ motifs (Fig. 7A). Late domain motif mutations in the hybrid GagGRA14 protein disrupted the release of HIV-1 VLPs, suggesting that these motifs encoded in TgGRA14 are important in the context of ESCRT-dependent HIV-1 budding process (Fig. 7B).

Next, to determine if TgGRA14 late domain motifs contribute to the recruitment of ESCRT and uptake of host cytosolic proteins, we complemented the R $\Delta$ gra14 strain with TgGRA14 encoding late domain motif mutations (Fig. S4). Complementation of R $\Delta$ gra14 with wildtype TgGRA14 $\left(\mathrm{R} \Delta\right.$ gra14GRA14 $\left.{ }^{W T}\right)$ or TgGRA14 encoding mutations in the $\mathrm{YPX}_{(\mathrm{n})} \mathrm{L}\left(\mathrm{R} \Delta\right.$ gra14GRA14 $\left.{ }^{A L I X-}\right)$ restored recruitment of GFP-TSG101 (Fig. 8A-8B and Fig. S6). However, complementation of R $\Delta$ gra14 with TgGRA14 constructs encoding PTAP mutations (RAgra14GRA14 ${ }^{\text {TSG101- }}$ and RAgra14GRA14 ${ }^{\text {TSG101-ALIX- }}$ ) were impaired in the recruitment of GFP-TSG101 to the PV (Fig. 8A and 8B and Fig. S6). These findings are consistent with TgGRA14 interacting with TSG101 through the PTAP motif. Unexpectedly, however, parasites expressing TgGRA14 late domain motif mutations showed normal internalization of host cytosolic proteins (Fig. $\mathbf{8 C}$ ). Taken together, these findings suggest that TgGRA14 late domain motifs are necessary for functional interaction with host ESCRT in the context of viral budding and GFP-TSG101 recruitment, but not for parasite ingestion of host cytosolic proteins. 


\section{Discussion}

Herein we show that host ESCRT and TgGRA14 are necessary for parasite ingestion of host cytosolic protein, that TgGRA14 has motifs that support ESCRT-dependent budding of VLPs, and that TgGRA14 co-immunoprecipitates with components of host ESCRT and other parasite secretory proteins in the setting of different parasite growth conditions (e.g. tachyzoite vs. bradyzoite) and host cell environments (e.g. human fibroblasts vs. mouse neurons). We also establish a contribution of TgGRA14 to the PV recruitment of the ESCRT-I protein TSG101 in a manner dependent upon a PTAP motif in the cytosolically exposed C-terminal domain of GRA14. Further, our findings suggest that expression of TgGRA14 is not necessary for PV recruitment of ALIX despite TgGRA14 having a putative ALIX interaction motif. Finally, we found that although GRA14 is necessary for parasite uptake of host protein, its TSG101 and ALIX motifs are dispensable for this process.

Whereas ESCRT and TgGRA14 are both required for the ingestion pathway late during infection, parasite ingestion of host cytosolic protein soon after invasion depends on ESCRT, but not TgGRA14. This suggests that early in infection $T$. gondii interacts with the host ESCRT machinery through a different mechanism. Although it has been shown that GRA proteins are secreted into the PV within the 30 min post-invasion ${ }^{33}$, it is unclear how long it takes them to reach their correct destinations and become functional thereafter. By contrast at least some proteins discharged from the parasite rhoptries during invasion are immediately functional since several are required for entry including those released from the rhoptry neck (RON proteins). Indeed, prior work showed that RON4 and RON5 interact with host ALIX and TSG101, respectively ${ }^{9}$. The function of TSG101 and ALIX during T. gondii invasion appears to be mainly as adaptor proteins for interaction with the host cytoskeleton and is likely independent of their roles in vesicle budding ${ }^{9}$. However, RON proteins remain associated with a discrete region of the nascent PVM for some time after invasion ${ }^{42}$, raising the possibility that they could function in ESCRT-dependent parasite uptake of host cytosolic protein. Additional studies are necessary to test this possibility. 
The abundant strategies used by pathogens to subvert the host ESCRT machinery highlight the importance of this host pathway in microbial pathogenesis. The multiple functions of the machinery in the cells provide numerous possibilities for an intracellular pathogen to benefit from it. This is not limited to mammalian host cells and their pathogens, since ESCRT-III and VPS4A homologs can be found in archaea Sulfolobus spp. ${ }^{43,44}$ and they are exploited by the archaeal Sulfolobus turreted icosahedral virus (STIV) for replication ${ }^{45}$. The best described examples of a pathogen usurping the ESCRT machinery are seen in viral egress from the host cell, this is the case for multiple enveloped viruses such as $\mathrm{HIV}^{17}$, the equine infectious anemia virus $(\mathrm{EIAV})^{41}$, and the Ebola virus ${ }^{22,23}$. Although a role for the ESCRT-III homologs has not been defined, a similar observation of ring-like structures at budding sites has been described for the archaeal Sulfolobus spindle-shaped virus-1 (SSV1) ${ }^{46}$. The known mechanisms for enveloped virus recruitment of eukaryotic host cell ESCRT machinery in viral budding is through pathogen proteins encoding late domain motifs, PTAP, YPX ${ }_{(n)} L$ and PPXY, which mimic motifs present in ESCRT components and are necessary for the assembly of the machinery ${ }^{15,47}$. These motifs are present in the C-terminus of our candidate $T$. gondii ESCRT-interacting protein TgGRA14. Because the most predominant late domain motifs in viral budding are PTAP and $\mathrm{YPX}(\mathrm{n}) \mathrm{L}$, we decided to elucidate their function in TgGRA14.

Our data demonstrates that the C-terminus portion of TgGRA14 is sufficient to substitute for the HIV-1 p6 domain, providing evidence that these late domain motifs encoded in TgGRA14 can recruit the host ESCRT machinery for vesicle formation in HIV-1 VLP release. Mutations in TgGRA14 late domain motifs impaired HIV-1 VLP release and mutations in the PTAP motif impaired GFP-TSG101 recruitment. Nonetheless, mutations in the late domain motifs had no apparent effect in the uptake of host cytosolic proteins suggesting that there might be alternative mechanisms for the ESCRT recruitment by TgGRA14 or additional effector proteins that function in concert with or in parallel to 
TgGRA14 for protein ingestion. It is, however, also possible that our current assay for ingestion is not sensitive enough to detect changes in the dynamics of this process, like slower rates of uptake.

The presence of a PPYPXXXXYP motif in TgGRA14 for the putative interaction with the host ALG-2 hints at an alternative mechanism by which TgGRA14 could interact with the host ESCRT machinery. The ESCRT adaptor protein ALG-2 is capable of interacting with both TSG10148 and ALIX ${ }^{49,50}$, and it can also stabilize an interaction between these two proteins in a $\mathrm{Ca}^{2+}$ dependent manner ${ }^{51}$. ALG-2 functions as an adaptor protein for the assembly of the ESCRT machinery at sites of membrane injury ${ }^{39}$ and it regulates ALIX function in MVB cargo sorting ${ }^{38}$. This host protein is highly enriched in the PV based on our immunoprecipitation data and others (Cygan, A. M. et al 2021) ${ }^{10}$ and although its role at this site remains to be elucidated, it could be acting as a bridge to promote the interaction between ESCRT components. The involvement of ALG-2 could suggest a role for $\mathrm{Ca}^{2+}$ in the function of the host ESCRT at the PVM. Further analysis of our TgGRA14 immunoprecipitation data looking for interacting parasite effector proteins encoding putative late domain motifs identified TgGRA8 and TgGRA4 as alternative candidates for the recruitment of ALG-2. However, the topology of these dense granule proteins at the PVM, their ability to interact with ESCRT components and function in ingestion remain to be elucidated. Also, additional dense granule proteins that do not encode putative late domain motifs could still be playing a role in ESCRT function at the PVM. This is the case for several intracellular pathogens which manipulate host ESCRT machinery via mechanisms that appear to be independent of late domain motif mediated interactions. Thus, it is conceivable that other T. gondii effector proteins could be interacting with the host ESCRT machinery in conjunction or independently of TgGRA14. This may explain the ALIX recruitment and residual GFP-TSG101 recruitment to the PV in TgGRA14deficient parasites. Future studies should focus on defining if TgGRA14 is working in a complex with other dense granule proteins for the recruitment of the host ESCRT machinery in the uptake of host cytosolic proteins. This would help us understand why there is no virulence defect in TgGRA14- 
deficient parasites ${ }^{26}$ and the importance of the uptake of host cytosolic proteins in T. gondii pathogenesis.

Since ALIX is still recruited to the PV of TgGRA14-deficient parasites, it is conceivable that other transmembrane dense granule proteins are contributing to the interaction with the host ESCRT components at the PV and compensating for the loss of TgGRA14. TgGRA15 is an interesting TgGRA14-interacting protein since it has also been demonstrated by immunoprecipitation to interact with several ESCRT components ${ }^{52}$. Although its role in the recruitment of the ESCRT machinery remains to be further elucidated, the known function of TgGRA15 in in type II strains is to modulate the host signaling pathway through NF-KB activation ${ }^{53}$. The extent to which TgGRA15 or other TgGRA14interacting dense granule proteins take part in the uptake of host cytosolic proteins remains unknown. The role of TgGRA7 in the context of host cytosolic protein uptake by $T$. gondii has been studied, but it does not seem to be contributing to this pathway ${ }^{4}$. The emerging picture is that $T$. gondii has the potential to subvert host ESCRT through a variety of means, which could indicate that it has evolved multiple mechanisms because of a critical reliance on host ESCRT.

Based on our findings, we propose a working model in which T. gondii acquires host cytosolic proteins by vesicular trafficking across the PVM happening through the interaction of the host ESCRT machinery with TgGRA14 (Fig. 9). This model posits that TgGRA14 functions as an ESCRT-adaptor for the recruitment of ESCRT-I components that subsequently interact with the accessory ESCRT protein ALIX, involved in bridging the ESCRT-I and ESCRT-III complexes. Although our work exposes the first mechanistic insight into how T. gondii recruits host ESCRT to the PVM during intracellular replication, much remains to be learned about the role of TgGRA14 and other parasite secretory proteins in this process. 


\section{Materials and Methods}

\section{Host cell and parasite culture}

Toxoplasma gondii cultures were maintained in human foreskin fibroblasts (HFF). RHAgra14 and RH GRA14-HA (R:GRA14OE) strains were kindly provided by Dr. Peter Bradley of the University of California in Los Angeles (UCLA). The ME49 $\Delta$ ku80 strain has been described previously ${ }^{54}$.

HFF, HeLa cells, GFP-TSG101 HeLa and Inducible mCherry HeLa cells were maintained in Dulbecco's modified Eagle's medium (DMEM) supplemented with 10\% Cosmic Calf serum, 20 mM HEPES, 5 $\mu \mathrm{g} / \mathrm{mL}$ penicillin/ streptomycin and $2 \mathrm{mM} \mathrm{L-glutamine.} \mathrm{Chinese} \mathrm{hamster} \mathrm{ovary}(\mathrm{CHO})$ cells were maintained in Ham's F12 supplemented with 10\% Cosmic Calf serum, 20 mM HEPES, $5 \mu \mathrm{g} / \mathrm{mL}$ penicillin/ streptomycin and $2 \mathrm{mM} \mathrm{L-glutamine.} \mathrm{For} \mathrm{bradyzoite} \mathrm{growth} \mathrm{conditions,} \mathrm{induction} \mathrm{media} \mathrm{was}$ used at the time of HFF infection (DMEM, 50mM HEPES, pH 8.2, 1\% FBS) and cultures kept in an ambient air $37^{\circ} \mathrm{C}$ incubator. For mouse primary cortical neuron infection, pregnant $\mathrm{C} 57 \mathrm{BI} / 6$ mice (Charles River) were euthanized to harvest brains from E15 mouse embryos, from which cortical neurons were dissected. Culture dishes $(15 \mathrm{~cm})$ coated with poly-L-lysine were plated with $6 \times 10^{6}$ neurons each and cultures maintained in Neurobasal media (Thermo Fisher) supplemented with GlutaMAX (Thermo Fisher) and B-27 (Gibco). Cytarabine was added to cultures on DIV4 to minimize non-neuronal contamination. Cultures were maintained up to DIV16 before infection with parasites.

\section{Bioinformatic search strategy}

To identify T. gondii proteins encoding late domain motif predicted to interact with the host TSG101 ESCRT-I protein, we performed a search in the Toxoplasma informatics resource ToxoDB. The first step in the search strategy consisted of the identification of genes encoding the $\mathrm{P}-[\mathrm{S} / \mathrm{T}]-\mathrm{A}-\mathrm{P}$ protein motif pattern and this resulted in an output of 620 genes. As a second step we looked for genes that encoded a signal peptide which resulted in 33 candidate proteins (Table S1). Further analysis of 
candidate genes using the hyperplexed localization of organelle proteins by isotype tagging (hyperLOPIT) data set ${ }^{34}$ allowed us to predict the localization of these proteins.

\section{Generation of parasite strains}

Insertion of the DNA sequence coding for 6x-HA epitopes before the stop codon of TgGRA14 was obtained by transfecting ME49 $\Delta k u 80 \Delta h x g$ with the vector GRA14/gRNA2 and a repair template coding for $6 \mathrm{x}-\mathrm{HA}$ fused at the 5'- and 3'-end to the 40 base pairs upstream and downstream the TgGRA14 stop codon, respectively. Since the vector GRA14/gRNA2 also carried the bleomycin resistance cassette, 24 hpi post transfection parasites were mechanically extruded from HFF using a 26G needle, filter purified and treated for $4 \mathrm{~h}$ with $50 \mu \mathrm{g} / \mathrm{ml}$ of bleomycin at $37^{\circ} \mathrm{C}$ to enrich for parasites that received the CRISPR/Cas9 vector. Bleomycin-treated parasites were allowed to expand in HFF monolayer until sufficient for cloning into 96-well plates to isolate single clones. Identification of clones carrying the correct integration of the $6 \mathrm{x}-\mathrm{HA}$ tag was carried out as described previously ${ }^{55}$ using primer pair P9 and P10 (Table S6) to detect fusion of the tag to the TgGRA14 end. The ME49 $\Delta$ ku80 GRA14-HA $6 x$ strain was further validated by immunofluorescence using anti-GRA14 and anti-HA.

To knockout TgGRA14 in a type II strain, CRISPR-Cas 9 gene editing was used to disrupt the gene in the ME49 $\Delta k u 80 \Delta h x g$ parasites. ME49 $\Delta k u 80 \Delta h x g$ was generated by transfecting ME49 $\Delta k u 80$ tachyzoites with $150 \mu \mathrm{g}$ of a vector expressing Cas9 and two guide RNAs targeting the 5'- (gRNA1 5'GGCUUGUUGUUUCCGUGCAG -3') and 3'- (gRNA2 5'- ACGUUAGUAAACUAACGCA -3') ends of the coding region of the HXGPRT gene and $10 \mu \mathrm{g}$ of a repair template. The repair template was obtained by annealing the two complementary 80 bp oligonucleotides P15 and P16 (Table S6). composed of the fusion of $40 \mathrm{bp}$ sequences that are homologous to sequences upstream and downstream of the Cas9 cleavages sites in the HXGPRT gene, respectively. After transfection, parasites were grown in presence of 6-thioxanthine $(200 \mu \mathrm{g} / \mathrm{ml})$ for 1 week and then cloned. Deletion of the HXGPRT gene was tested by PCR $(\mathrm{P} 17+\mathrm{P} 20$ and P18 + P19 for the absence of the HXGPRT gene and P17 + P18 to 
assess the size of the genome fragment left between the 2 Cas9 cuts) and sensitivity to mycophenolic acid (MPA; $25 \mu \mathrm{g} / \mathrm{ml})$ and xanthine $(50 \mu \mathrm{g} / \mathrm{ml})$.

Deletion of the TgGRA14 gene was obtained transfecting the strain ME49 $\Delta k u 80 \Delta h \times g$ with the vectors GRA14/gRNA1 and GRA14/gRNA2, expressing Cas9 and gRNAs (gRNA1: 5'-

GCTAGCAGAGGTGAATGTAA-3'; gRNA2: 5'-CCAGAGACCAAGCGAATAGA-3') directing Cas9 nuclease to cut the TgGRA14 gene upstream the start codon and over the stop codon, respectively, along with a repair template carrying the HXGPRT (HXG) resistance cassette flanked at its 5'- and 3'ends by 40 base pairs homologue to the regions immediately upstream and downstream the two Cas 9 cuts, respectively. After selecting for HXG resistant with mycophenolic acid $(25 \mu \mathrm{g} / \mathrm{ml})$ and xanthine (50 $\mu \mathrm{g} / \mathrm{ml}$ ), parasites were cloned in 96 well-plates and single plaques were screened as previously described ${ }^{55}$ using primers to detect the absence of the TgGRA14 gene using primers P3 and P4 (Table S6). The ME49 $\Delta k u 80 \Delta$ gra14 strain was further validated by immunoblot by probing for GRA14.

$\mathrm{RH} \Delta$ gra14 complementation strains were generated by transfecting the parasites with pGRA14-

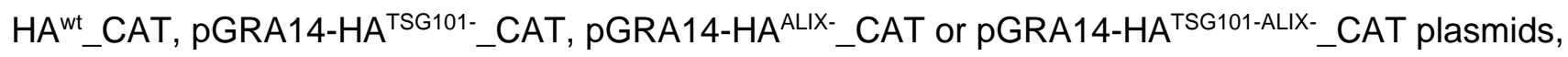
linearized using FspAI (Thermo Fisher Scientific, Cat \#ER1661). Post-transfection, the parasites were selected with chloramphenicol $20 \mu \mathrm{M}$ and clones confirmed by PCR using the primer pair P9 and P10, Immunofluorescence and immunoblot by probing for GRA14 and HA.

\section{Transient transfection of host cells}

To transfect HeLa cells, $4.0 \times 10^{5}$ cells were seeded per well in a 6 -well plate. Each well was transfected with $2 \mu \mathrm{g}$ of DNA using Lipofectamine 2000 (Thermo Fisher Scientific, Cat\# 11668027) transfection reagent following the manufacturer's instructions. Cells were either fixed or infected at 16-18 h posttransfection. 


\section{Immunofluorescence and immunoblot}

Samples were fixed with 4\% methanol-free paraformaldehyde (PFA) in PBS for 10 min, permeabilized with $0.1 \%$ Triton X-100 for 10 min and blocked with $10 \%$ FBS for 20 min. Primary and secondary antibodies were diluted in $1 \%$ FBS prior to $1 \mathrm{~h}$ incubations at RT. Images were taken using a Zeiss Axiovert Observer fluorescence microscope, a Nikon X1 Yokogawa spinning disk confocal microscope, Nikon Structured Illumination microscope, Nikon X1 Yokogawa Spinning disk confocal or a Yokogawa CellVoyager 8000 spinning disc confocal high content imaging instrument.

Nitrocellulose membranes were blocked with $5 \%$ milk prior to primary antibody incubation and subsequently incubated with horseradish peroxidase (HRP) conjugated secondary antibodies. For detection, the membranes were incubated for 2 min with the SuperSignal West Pico PLUS Chemiluminescent substrate (Thermo Fisher Scientific, Cat\# 34580). Chemiluminescent signal was visualized using the Syngene PXi6 imaging system.

\section{Growth assay following ESCRT disruption}

The plasmids for the expression of VPS4A ${ }^{W T}$ and VPS4A ${ }^{E Q}$ were kindly provided by Dr. Akira Ono (University of Michigan). HeLa cells were grown on coverslips and transiently transfected with either pVPS4A_WT-mCherry or pVPS4A_EQ-mCherry. The monolayer was infected with $1.2 \times 10^{6} \mathrm{RH}$ parasites, then fixed at 24 hpi with 4\% PFA. To visualize individual parasites and delineate the PV, the coverslips were stained with rabbit anti-GAP45 and mouse anti-GRA7. The number of parasites per vacuole was quantified for transfected cells, identified by the expression of mCherry, and untransfected cells. Seven biological replicates were collected and at least 20 PVs analyzed per replicate as blinded samples. 


\section{Parasite ingestion assay following ESCRT disruption}

HeLa or $\mathrm{CHO}$ cells were transiently transfected with $2 \mu \mathrm{g}$ of pVenus, for the expression of cytosolic fluorescent reporter, and $1 \mu \mathrm{g}$ of either pVPS4A_WT-mCherry or pVPS4A_EQ-mCherry as described above. Following overnight incubation, the cells were infected with $5.0 \times 10^{5}$ parasites per well. As a negative control, RH WT strain was used to infect cells expressing only pVenus. To detect internalized host-derived cytosolic material we used the $\mathrm{RH} \Delta c p$ / strain to infect cells expressing pVenus, as a positive control, and cells co-transfected with pVenus and pVPS4A-mCherry isoforms. At 24 hpi parasites were harvested as previously described ${ }^{4}$. Briefly, parasites were harvested on ice by scraping and syringing. The parasites were then treated with a $1 \mathrm{mg} / \mathrm{mL}$ pronase $-0.01 \%$ saponin-PBS solution for $1 \mathrm{~h}$ at $12^{\circ} \mathrm{C}$, centrifuged at $1,000 \mathrm{~g}$ for $10 \mathrm{~min}$ and washed 3 times before adding to Cell-Tak coated slides. The parasites were fixed and permeabilized with $0.1 \%$ Triton X-100 prior to imaging.

\section{Virus-like particle assay}

The plasmids pGag_Venus, pRev and pVphu were used for the generation of HIV virus-like particles as previously described ${ }^{56-58}$. To delete the $p 6$ domain encoding the late domain motifs and generate pGag $\Delta p 6$ _Venus, pGag_Venus was linearized using Swal and Smal. To introduce back the encoding region upstream of the p6 domain the encoding region from the 664-base pair (bp) to 1456 bp (a 793 bp fragment-Gaglnsert) was generated by PCR and introduced into the linearized pGag_Venus by Gibson assembly. For the generation of the pGagGRA14_Venus construct, in addition to the Gaglnsert, a second insert was made by amplifying TgGRA14 C-terminus from T. gondii cDNA (Region encoding 1457-1759 bp-GRA14CtermInsert) and both fragments were introduced into the linearized pGag_Venus vector by Gibson Assembly. The plasmids were confirmed by Sanger Sequencing using the primer P8.

HIV-1 Gag virus-like particles (VLPs) were collected as previously described ${ }^{56}$. Briefly, HeLa cells were transfected with pRev, pVphu and pGag_Venus constructs using Lipofectamine 2000. Following 
overnight incubation, the supernatant containing the released VLPs was filtered and ultracentrifuged at 35,000 rpms for $45 \mathrm{~min}$ at $4^{\circ} \mathrm{C}$ to collect the VLP pellets which were then lysed with $0.5 \%$ Triton X-lysis buffer. The cell lysates were prepared by lysing the monolayer with the same lysis buffer. The lysates (obtained by loading 100\% VLP and 4\% cell lysates on SDS-PAGE gel) were analyzed by immunoblot using a human anti-Gag. Band intensity was quantified using Image J. Total Gag corresponds to the sum of cell- and VLP-associated Gag. The VLP release efficiency corresponds to the fraction of Gag that was released as VLP relative to the total Gag.

\section{Generation of plasmids encoding GRA14 late-domain mutants.}

The predicted late domain motifs encoded in TgGRA14 C-terminus were mutated in the pGagGRA14_Venus by site-directed mutagenesis (Q5 Site-Directed mutagenesis kit NEB, Cat\#E0554S). Primers encoding mutation alanine substitutions for PTAP or YPXL were used to

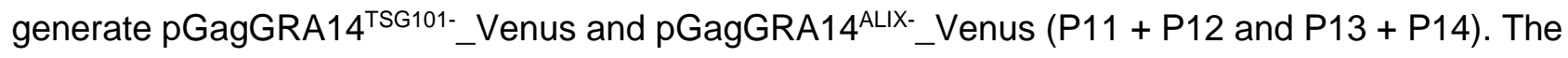

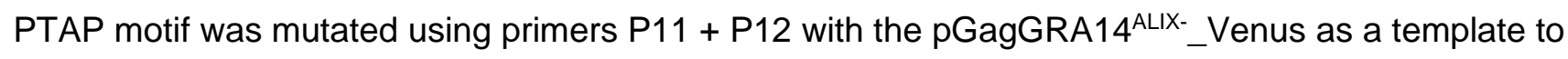

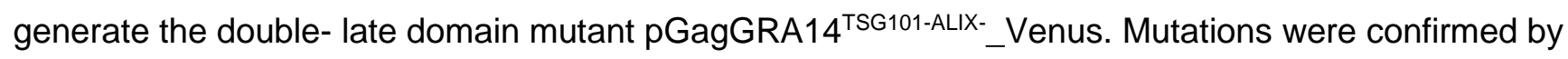
Sanger Sequencing using the primer P8.

To generate pGRA14-HA_CAT plasmid encoding late domain motif mutations, a chloramphenicol selectable marker was introduced into the pGRA14-HA plasmid kindly provided by Dr. Peter Bradley. The pGRA14-HA and pTub_CAT plasmid was digested with Apal and Xbal. The chloramphenicol selectable marker was gel-purified and was ligated to the vector (linearized pGRA14-HA) following incubation with the T4 DNA ligase. The construct was transformed into $\mathrm{DH} 5 \mathrm{a}$ and single colonies analyzed for correct insertion of the selectable marker cassette using Ncol and Notl, two unique restriction enzymes that would generate a $3.5 \mathrm{~kb}$ product in pGRA14-HA_CAT and not pGRA14-HA. Late-domain motif mutations in pGRA14-HA_CAT was generated by site directed mutagenesis as described above $\left(\mathrm{P} 11+\mathrm{P} 12\right.$ and P13 + P14). The plasmids pGRA14-HA ${ }^{\text {wt }}$ CAT, pGRA14-HA ${ }^{\text {TSG101- }}$ 


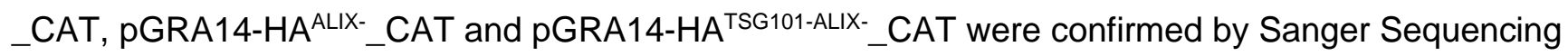
using primer P8.

\section{Proximity Ligation Assay (PLA)}

Proximity ligation assay (PLA) was performed using the Duolink In Situ Red Started Kit Mouse/Rabbit (Millipore Sigma, Cat\# DUO92101-1KT) following manufacturer's instructions. Briefly, wildtype HeLa or GFP-TSG101 HeLa cells were seeded in coverslips and infected with either RH or RH:GRA14OE. At 24 hpi the infected monolayer was fixed with 4\% PFA and permeabilized with $0.1 \%$ Triton X-100 for 10 min. In a humidity chamber, the samples were blocked using Duolink blocking buffer at $37^{\circ} \mathrm{C}$ for $1 \mathrm{~h}$ then incubated with primary antibody at room temperatures for $1 \mathrm{~h}$. The coverslips were incubated with the PLA secondary antibodies anti-Rabbit PLUS and anti-Mouse MINUS for $1 \mathrm{~h}$ at $37^{\circ} \mathrm{C}$ followed by a ligation step for $30 \mathrm{~min}$ and a final amplification step for $100 \mathrm{~min}$, both also at $37^{\circ} \mathrm{C}$. Samples of HeLa cells infected with $\mathrm{RH}$ strain were used as a negative control.

\section{GRA14-HA Immunoprecipitation}

HFFs or mouse primary neurons were grown in $15 \mathrm{~cm}$ dishes and infected with $3-4.5 \times 10^{7}$ or $1.5-2 \times 10^{7}$ parasites respectively per dish using either ME49 $\Delta$ ku80 GRA14-HA $6 x$ or the untagged control ME49 $\Delta$ ku80. For bradyzoite infection conditions, 15cm HFF cultures were infected in bradyzoite induction media with $1.5 \times 10^{7}$ parasites per dish. At 48 hpi (or $72 \mathrm{hpi}$ for bradyzoite conditions), the samples were washed with cold 1x PBS three times and before scrapping the samples in cold lysis buffer (50 mM Tris pH 7.6, $200 \mathrm{mM} \mathrm{NaCl,} \mathrm{1 \%} \mathrm{Triton} \mathrm{X-100,} \mathrm{0.5 \%} \mathrm{CHAPS} \mathrm{+} \mathrm{complete} \mathrm{protease}$ inhibitor/Roche Cat\# 11836153001). The samples were mechanically disrupted by passing them through a 27.5 syringe five times before sonication on ice ( $1 \mathrm{sec}$ on, $1 \mathrm{sec}$ off, $20 \%$ amplitude, 30 cycles). After a $30 \mathrm{~min}$ incubation on ice, the lysed samples were centrifuged at $1,000 \mathrm{xg}$ for $10 \mathrm{~min}$ at $4^{\circ} \mathrm{C}$ to remove any remaining intact cells. The supernatant was collected (Input sample) and incubated overnight with anti-HA magnetic beads (Pierce, Cat\# 88836). Following incubation, the beads were 
collected on a magnetic stand for 2 min and washed four times with lysis buffer and four times with wash buffer (50mM Tris pH 7.6, 300mM NaCl, 1\% Triton X-100, + complete protease inhibitor/ Roche Cat\# 11836153001). The beads were resuspended in 1x Laemmli sample buffer, boiled for 5 min, and the immunoprecipitated protein eluted by collecting the supernatant following incubation in the magnetic stand for 2 min. The collected immunoprecipitated proteins were reduced, alkylated, and digested into peptides with trypsin on S-Trap micro columns (Protifi) per manufacturer instructions.

\section{LC-MS/MS Acquisition and Analysis}

For peptide samples from all Co-IP experiments, samples were resuspended in $10 \mu \mathrm{l}$ of water $+0.1 \%$ TFA and loaded onto a Dionex RSLC Ultimate 300 (Thermo Scientific, San Jose, CA, USA), coupled online with an Orbitrap Fusion Lumos (Thermo Scientific). The mass spectrometer was set to acquire spectra in a data-dependent acquisition (DDA) mode. Briefly, the full MS scan was set to 300$1200 \mathrm{~m} / \mathrm{z}$ in the orbitrap with a resolution of 120,000 (at $200 \mathrm{~m} / \mathrm{z}$ ) and an AGC target of 5x10e5. MS/MS was performed in the ion trap using the top speed mode (2 secs), an AGC target of 10e4 and an HCD collision energy of 30. Raw files were searched using Proteome Discoverer software (v2.4, Thermo Scientific) using SEQUEST as search engine. We used either the SwissProt human or mouse databases combined with the Toxoplasma database (Release 44, ME49 proteome obtained from ToxoDB). The search for total proteome included variable modifications of methionine oxidation and N-terminal acetylation, and fixed modification of carbamidomethyl cysteine. Trypsin was specified as the digestive enzyme. Mass tolerance was set to $10 \mathrm{pm}$ for precursor ions and $0.2 \mathrm{Da}$ for product ions. Peptide and protein false discovery rate was set to $1 \%$. For quantitative analysis, peptide intensity values were log2 transformed, normalized by the average value of each sample, and missing values were imputed using a normal distribution 2 standard deviations lower than the mean. Peptide $\log _{2}$ fold changes were then averaged to obtain a single protein $\log _{2}$ fold change. Statistical significance was assessed among the three replicates for each condition using a heteroscedastic T-test 
(if $p$-value < 0.05) comparing peptide quantification between test and control samples for each condition.

Mass spectrometry raw files are available on https://chorusproject.org/ at project number 1733.

\section{Parasite ingestion assay using Inducible mCherry HeLa cells}

Inducible mCherry HeLa cells were generated following the methods for generating the inducible mCherry CHO-K1 cells previously described ${ }^{3}$. Briefly, the cells were transfected with pTRE2-mCherry, for the mCherry expression under a tetracycline-inducible promoter, and pTet-ON, encoding the reverse tet-responsive transcriptional activator. Co-transfected cells were selected with $200 \mu \mathrm{g} / \mathrm{mL}$ hygromycin B and $200 \mu \mathrm{g} / \mathrm{mL}$ geneticin. Resistant cells were tested for their induction of mCherry following doxycycline treatment and were sorted for the brightest mCherry signal. For ingestion experiments, $1.5 \times 10^{5}$ cells are seeded per well in a 6 -well plate. Cytosolic mCherry expression is induced by adding $2 \mu \mathrm{g} / \mathrm{mL}$ doxycycline for 4-days. The cells are then infected with $5.0 \times 10^{5}$ type I parasites or $1.0 \times 10^{6}$ type II parasites. For the 4 hpi time point, the parasites were then treated with 5 $\mu \mathrm{M}$ LHVS for $24 \mathrm{~h}$ prior to infection of mCherry+ cells.

For the 24 hpi time point, the monolayer was washed at $4 \mathrm{hpi}$ and fresh media containing $5 \mu \mathrm{M}$ LHVS is added for 20 h. Parasites were harvested as previously described.

\section{ALIX and GFP-TSG101 recruitment}

HeLa cells expressing endogenously tagged GFP-TSG101 were grown on coverslips and infected with R:GRA14oe parasites for $24 \mathrm{~h}$. The samples were fixed and stained for anti-ALIX and anti-HA as described above. Samples were imaged and reconstructed using a Nikon A1R structured illumination microscope. 
bioRxiv preprint doi: https://doi.org/10.1101/2021.07.21.453261; this version posted July 21, 2021. The copyright holder for this preprint (which

was not certified by peer review) is the author/funder, who has granted bioRxiv a license to display the preprint in perpetuity. It is made available under aCC-BY-NC 4.0 International license.

Initially the recruitment of ALIX in GFP-TSG101 infected cells was analyzed by staining the samples with anti-HA and anti-GRA8 as a marker for the PVM and anti-GAP45 to label the parasites. Samples were imaged using a Nikon X1 Yokogawa Spinning disk confocal.

To compare the recruitment of ALIX between WT, TgGRA14-deficient parasites and a TgGRA14 overexpressing strain, HeLa cells were seeded in a poly-D-lysine coated 384 well plate (4,000 cells per well) $2 \mathrm{~h}$ prior to infection with either RH, RAgra14 and R:GRA14OE at a MOI 5 for $24 \mathrm{~h}$. The 384-well plate was fixed and stained for anti-ALIX, anti-GRA1, HCS CellMask Deep Red (CMDR, ThermoFisher) and Hoechst (Sigma). For the analysis for the recruitment of TSG101, GFP-TSG101 HeLa cells were seeded in a 384 well plate $2 \mathrm{~h}$ prior to infection with either $\mathrm{RH}, \mathrm{R} \Delta$ gra14, R:GRA14 $\mathrm{OE}$ and $\mathrm{R} \Delta \mathrm{gra} 14$ complementation strains at a MOI 5 for $24 \mathrm{~h}$. The 384-well plate was fixed and stained for anti-GRA1, HCS CellMask Deep Red (CMDR, ThermoFisher) and Hoechst (Sigma).

Both plates were imaged at 20x using a Yokogawa CellVoyager 8000 spinning disc confocal high content imaging instrument. 9 fields of view (FOV) were captured from each well. A Z-stack spanning $10 \mu \mathrm{m}$ with $1 \mu \mathrm{m}$ intervals was captured for each FOV. Z-stacks for each channel were then collapsed into maximum intensity projections (MIP). To quantify the recruitment of TSG101 and ALIX to the parasite, CellProfiler was used to identify cells (CMDR MIP), nuclei (Hoechst MIP), cell cytoplasm (cell area occluding nucleus) and Toxoplasma (GRA1 MIP) and capture intensity measurements of TSG101 or ALIX in each cellular compartment. The intensity of TSG101 or ALIX in the parasite and cytoplasm was then normalized to background (define as the lowest intensity in each cell). The normalized intensity of TSG101 or ALIX within Toxoplasma was then related to the cytoplasm. All calculations were performed in KNIME. Cells with multiple PVs were excluded from the analysis. 
bioRxiv preprint doi: https://doi.org/10.1101/2021.07.21.453261; this version posted July 21,2021 . The copyright holder for this preprint (which

was not certified by peer review) is the author/funder, who has granted bioRxiv a license to display the preprint in perpetuity. It is made available under aCC-BY-NC 4.0 International license.

\section{Ethics Statement}

Mouse husbandry and primary neuron dissections were conducted according to guidelines from the United States Public Health Service Policy on Humane Care and Use of Laboratory Animals. Animals were maintained in an AAALAC-approved facility, and all protocols were approved by the Institutional Care Committee of the Albert Einstein College of Medicine, Bronx, NY (Animal Protocol 20180602; Animal Welfare Assurance no. A3312-01). 


\section{$\underline{\text { References }}$}

1. Mercier, C. \& Cesbron-Delauw, M.-F. Toxoplasma secretory granules: one population or more? Trends Parasitol. 31, 60-71 (2015).

2. Wang, Y., Sangaré, L. O., Paredes-Santos, T. C. \& Saeij, J. P. J. Toxoplasma Mechanisms for Delivery of Proteins and Uptake of Nutrients Across the Host-Pathogen Interface. Annu Rev Microbiol 74, 567-586 (2020).

3. McGovern, O. L., Rivera-Cuevas, Y., Kannan, G., Narwold, A. J. \& Carruthers, V. B. Intersection of endocytic and exocytic systems in Toxoplasma gondii. Traffic 19, 336-353 (2018).

4. Dou, Z., McGovern, O. L., Di Cristina, M. \& Carruthers, V. B. Toxoplasma gondii ingests and digests host cytosolic proteins. MBio 5, e01188-01114 (2014).

5. Walker, M. E. et al. Toxoplasma gondii actively remodels the microtubule network in host cells. Microbes and Infection 10, 1440-1449 (2008).

6. Jones, T. C. \& Hirsch, J. G. The interaction between Toxoplasma gondii and mammalian cells. II. The absence of lysosomal fusion with phagocytic vacuoles containing living parasites. J Exp Med 136, 1173-94 (1972).

7. Sinai, A. P., Webster, P. \& Joiner, K. A. Association of host cell endoplasmic reticulum and mitochondria with the Toxoplasma gondii parasitophorous vacuole membrane: a high affinity interaction. J. Cell. Sci. 110 ( Pt 17), 2117-2128 (1997).

8. de Melo, E. J., de Carvalho, T. U. \& de Souza, W. Penetration of Toxoplasma gondii into host cells induces changes in the distribution of the mitochondria and the endoplasmic reticulum. Cell Struct. Funct. 17, 311-317 (1992).

9. Guerin, A. et al. Efficient invasion by Toxoplasma depends on the subversion of host protein networks. Nature microbiology 2, 1358-1366 (2017).

10. Cygan, A. M. et al. Proximity-labeling reveals novel host and parasite proteins at the Toxoplasma parasitophorous vacuole membrane. http://biorxiv.org/lookup/doi/10.1101/2021.02.02.429490 (2021) doi:10.1101/2021.02.02.429490.

11. Hurley, J. H. ESCRTs are everywhere. The EMBO Journal 34, 2398-2407 (2015).

12. Vietri, M., Radulovic, M. \& Stenmark, H. The many functions of ESCRTs. Nat Rev Mol Cell Biol 21, 25-42 (2020).

13. Hurley, J. H. The ESCRT complexes. Crit. Rev. Biochem. Mol. Biol. 45, 463-487 (2010).

14. Garrus, J. E. et al. Tsg101 and the Vacuolar Protein Sorting Pathway Are Essential for HIV-1 Budding. Cell 107, 55-65 (2001).

15. Pornillos, O. et al. HIV Gag mimics the Tsg101-recruiting activity of the human Hrs protein. J Cell Biol 162, 425-434 (2003). 
16. VerPlank, L. et al. Tsg101, a homologue of ubiquitin-conjugating (E2) enzymes, binds the L domain in HIV type 1 Pr55Gag. PNAS 98, 7724-7729 (2001).

17. von Schwedler, U. K. et al. The protein network of HIV budding. Cell 114, 701-713 (2003).

18. Bleck, M. et al. Temporal and spatial organization of ESCRT protein recruitment during HIV-1 budding. Proc. Natl. Acad. Sci. U.S.A. 111, 12211-12216 (2014).

19. Tabata, K. et al. Unique Requirement for ESCRT Factors in Flavivirus Particle Formation on the Endoplasmic Reticulum. Cell Rep 16, 2339-2347 (2016).

20. Corless, L., Crump, C. M., Griffin, S. D. C. \& Harris, M. Vps4 and the ESCRT-III complex are required for the release of infectious hepatitis C virus particles. J. Gen. Virol. 91, 362-372 (2010).

21. Barouch-Bentov, R. et al. Hepatitis C Virus Proteins Interact with the Endosomal Sorting Complex Required for Transport (ESCRT) Machinery via Ubiquitination To Facilitate Viral Envelopment. MBio 7, (2016).

22. Licata, J. M. et al. Overlapping motifs (PTAP and PPEY) within the Ebola virus VP40 protein function independently as late budding domains: involvement of host proteins TSG101 and VPS-4. J. Virol. 77, 1812-1819 (2003).

23. Irie, T., Licata, J. M. \& Harty, R. N. Functional characterization of Ebola virus L-domains using VSV recombinants. Virology 336, 291-298 (2005).

24. Mehra, A. et al. Mycobacterium tuberculosis type VII secreted effector EsxH targets host ESCRT to impair trafficking. PLoS Pathog. 9, e1003734 (2013).

25. Mittal, E. et al. Mycobacterium tuberculosis Type VII Secretion System Effectors Differentially Impact the ESCRT Endomembrane Damage Response. MBio 9, (2018).

26. Rome, M. E., Beck, J. R., Turetzky, J. M., Webster, P. \& Bradley, P. J. Intervacuolar transport and unique topology of GRA14, a novel dense granule protein in Toxoplasma gondii. Infect. Immun. 76, 4865-4875 (2008).

27. Hill, C. P. \& Babst, M. Structure and function of the membrane deformation AAA ATPase Vps4.

Biochimica et Biophysica Acta (BBA) - Molecular Cell Research 1823, 172-181 (2012).

28. Pfitzner, A.-K. et al. An ESCRT-III Polymerization Sequence Drives Membrane Deformation and Fission. Cell 182, 1140-1155.e18 (2020).

29. Bishop, N. \& Woodman, P. ATPase-defective Mammalian VPS4 Localizes to Aberrant Endosomes and Impairs Cholesterol Trafficking. Mol Biol Cell 11, 227-239 (2000).

30. Votteler, J. \& Sundquist, W. I. Virus Budding and the ESCRT Pathway. Cell Host Microbe 14, (2013).

31. Strack, B., Calistri, A., Craig, S., Popova, E. \& Göttlinger, H. G. AIP1/ALIX Is a Binding Partner for HIV-1 p6 and EIAV p9 Functioning in Virus Budding. Cell 114, 689-699 (2003).

32. Guérin, A. et al. Efficient invasion by Toxoplasma depends on the subversion of host protein networks. Nat Microbiol 2, 1358-1366 (2017).

33. V, C. \& Sibley, L. D. Sequential protein secretion from three distinct organelles of Toxoplasma gondii accompanies invasion of human fibroblasts. Eur J Cell Biol 73, 114-123 (1997). 
34. Barylyuk, K. et al. A Comprehensive Subcellular Atlas of the Toxoplasma Proteome via hyperLOPIT Provides Spatial Context for Protein Functions. Cell Host \& Microbe 28, 752-766.e9 (2020).

35. Hoffman, H. K., Fernandez, M. V., Groves, N. S., Freed, E. O. \& van Engelenburg, S. B. Genomic tagging of endogenous human ESCRT-I complex preserves ESCRT-mediated membrane-remodeling functions. J. Biol. Chem. 294, 16266-16281 (2019).

36. Kumar, B. et al. ESCRT-I Protein Tsg101 Plays a Role in the Post-macropinocytic Trafficking and Infection of Endothelial Cells by Kaposi's Sarcoma-Associated Herpesvirus. PLoS Pathog 12, e1005960 (2016).

37. Kumar, B., Veettil, M. V., Roy, A. \& Chandran, B. Proximity Ligation Assay (PLA) to Determine the Endosomal Localization of ESCRT Subunit in Virus-Infected Cells. Methods Mol. Biol. 1998, 63-72 (2019).

38. Sun, S. et al. ALG-2 activates the MVB sorting function of ALIX through relieving its intramolecular interaction. Cell Discov 1, 15018 (2015).

39. Scheffer, L. L. et al. Mechanism of Ca2+-triggered ESCRT assembly and regulation of cell membrane repair. Nat Commun 5, 5646 (2014).

40. Kitaura, Y., Matsumoto, S., Satoh, H., Hitomi, K. \& Maki, M. Peflin and ALG-2, Members of the Penta-EFHand Protein Family, Form a Heterodimer That Dissociates in a $\mathrm{Ca}^{2+}$-dependent Manner. J. Biol. Chem. 276, 14053-14058 (2001).

41. Sandrin, V. \& Sundquist, W. I. ESCRT requirements for EIAV budding. Retrovirology 10, 104 (2013).

42. Pavlou, G. et al. Toxoplasma Parasite Twisting Motion Mechanically Induces Host Cell Membrane Fission to Complete Invasion within a Protective Vacuole. Cell host \& microbe 24, 81-96.e5 (2018).

43. Obita, T. et al. Structural basis for selective recognition of ESCRT-III by the AAA ATPase Vps4. Nature 449, 735-739 (2007).

44. Hobel, C. F. V., Albers, S. V., Driessen, A. J. M. \& Lupas, A. N. The Sulfolobus solfataricus AAA protein Sso0909, a homologue of the eukaryotic ESCRT Vps4 ATPase. Biochemical Society Transactions 36, 94-98 (2008).

45. Snyder, J. C., Samson, R. Y., Brumfield, S. K., Bell, S. D. \& Young, M. J. Functional interplay between a virus and the ESCRT machinery in Archaea. PNAS 110, 10783-10787 (2013).

46. Quemin, E. R. J. et al. Eukaryotic-Like Virus Budding in Archaea. mBio 7, (2016).

47. Ren, X. \& Hurley, J. H. Proline-Rich Regions and Motifs in Trafficking: From ESCRT Interaction to Viral Exploitation. Traffic 12, 1282-1290 (2011).

48. Katoh, K. et al. The penta-EF-hand protein ALG-2 interacts directly with the ESCRT-I component TSG101, and $\mathrm{Ca2+-dependently} \mathrm{co-localizes} \mathrm{to} \mathrm{aberrant} \mathrm{endosomes} \mathrm{with} \mathrm{dominant-negative} \mathrm{AAA} \mathrm{ATPase} \mathrm{SKD1/Vps4B.}$ Biochem J 391, 677-685 (2005).

49. Vito, P., Pellegrini, L., Guiet, C. \& D’Adamio, L. Cloning of AIP1, a Novel Protein That Associates with the Apoptosis-linked Gene ALG-2 in a Ca2+-dependent Reaction*. Journal of Biological Chemistry 274, 1533-1540 (1999). 
50. Missotten, M., Nichols, A., Rieger, K. \& Sadoul, R. Alix, a novel mouse protein undergoing calciumdependent interaction with the apoptosis-linked-gene 2 (ALG-2) protein. Cell Death \& Differentiation 6, 124-129 (1999).

51. Okumura, M. et al. Penta-EF-hand protein ALG-2 functions as a Ca2+-dependent adaptor that bridges Alix and TSG101. Biochemical and Biophysical Research Communications 386, 237-241 (2009).

52. Mukhopadhyay, D., Sangaré, L. O., Braun, L., Hakimi, M. \& Saeij, J. P. Toxoplasma GRA15 limits parasite growth in IFNY-activated fibroblasts through TRAF ubiquitin ligases. EMBO J 39, (2020).

53. Rosowski, E. E. et al. Strain-specific activation of the NF-KB pathway by GRA15, a novel Toxoplasma gondii dense granule protein. Journal of Experimental Medicine 208, 195-212 (2011).

54. Waldman, B. S. et al. Identification of a Master Regulator of Differentiation in Toxoplasma. Cell 180, 359372.e16 (2020).

55. Piro, F., Carruthers, V. B. \& Di Cristina, M. PCR Screening of Toxoplasma gondii Single Clones Directly from 96-Well Plates Without DNA Purification. Methods Mol Biol 2071, 117-123 (2020).

56. Thornhill, D., Olety, B. \& Ono, A. Relationships between MA-RNA Binding in Cells and Suppression of HIV-1 Gag Mislocalization to Intracellular Membranes. J Virol 93, (2019).

57. Hogue, I. B., Grover, J. R., Soheilian, F., Nagashima, K. \& Ono, A. Gag induces the coalescence of clustered lipid rafts and tetraspanin-enriched microdomains at HIV-1 assembly sites on the plasma membrane. $J$ Virol 85, 9749-9766 (2011).

58. Nguyen, K.-L. et al. Codon optimization of the HIV-1 vpu and vif genes stabilizes their mRNA and allows for highly efficient Rev-independent expression. Virology 319, 163-175 (2004). 
Figure Legends

A

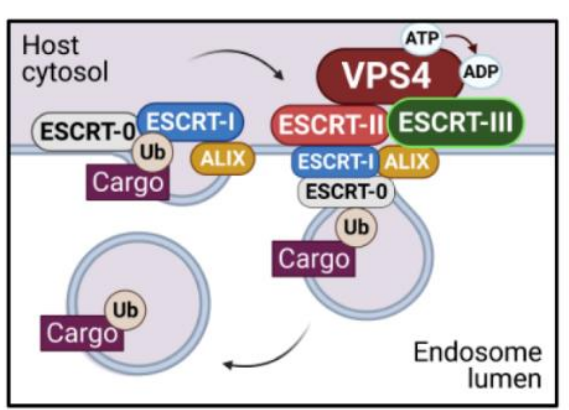

D

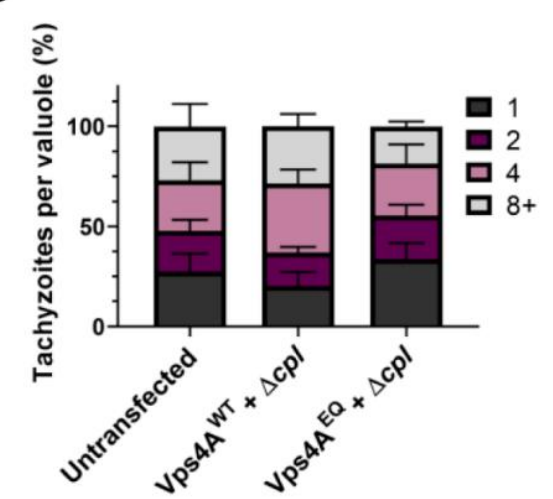

E

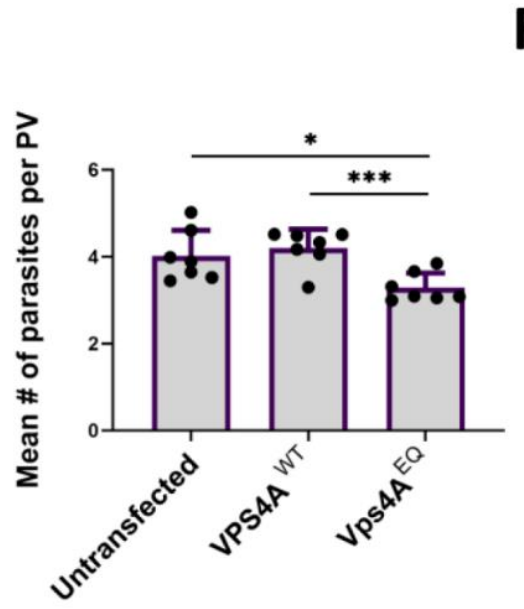

$\mathbf{F}$
B

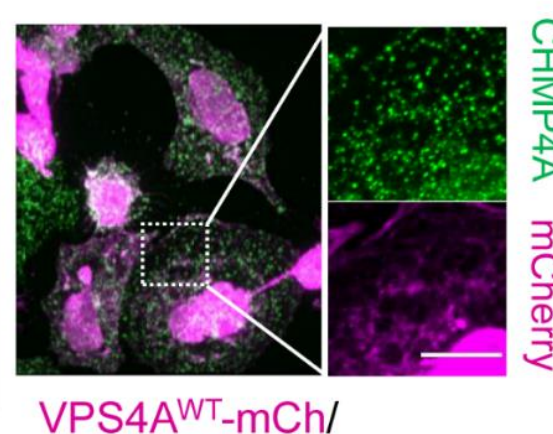

CHMP4A

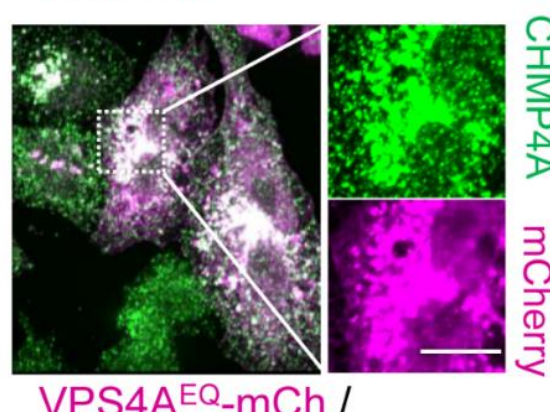

CHMP4A

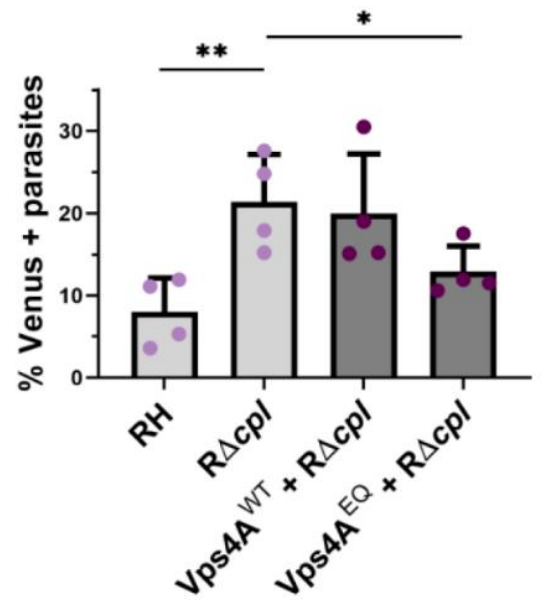

Newly invaded parasites
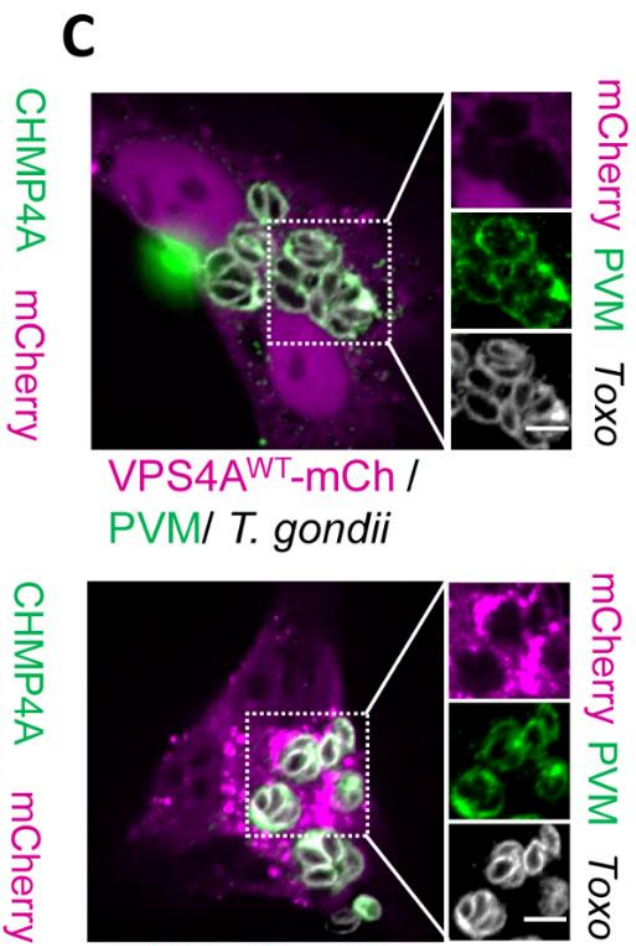

VPS4AEQ-mCh /

PVM/ T. gondii

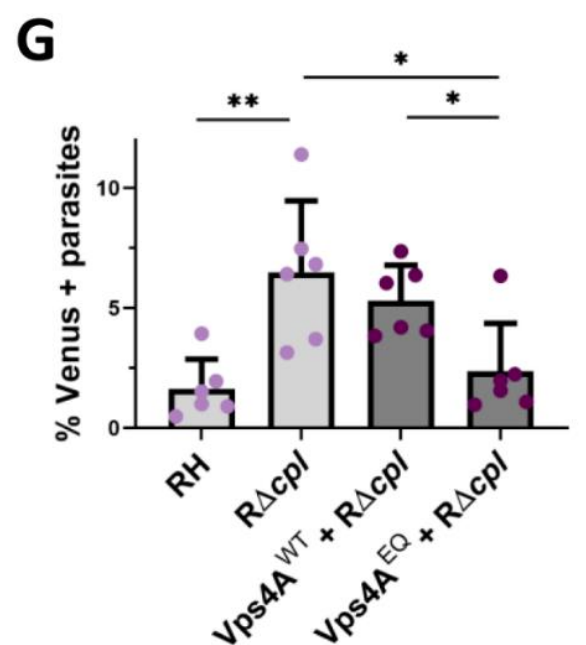

Replicating parasites 
bioRxiv preprint doi: https://doi.org/10.1101/2021.07.21.453261; this version posted July 21, 2021. The copyright holder for this preprint (which

was not certified by peer review) is the author/funder, who has granted bioRxiv a license to display the preprint in perpetuity. It is made available under aCC-BY-NC 4.0 International license.

Figure 1. Disruption of the host ESCRT machinery impairs uptake of host cytosolic proteins by Toxoplasma gondii.

A. Schematic of the ESCRT machinery function in MVB formation. Ubiquitinated cargo targeted for degradation is recognized by ESCRT-0 and ECSRT-I, which further recruits ESCRT-II and the ESCRT accessory protein ALIX. At the last steps, ESCRT-III forms spirals at the membrane to mediate membrane constriction and the VPS4 complex facilitates scission and disassembly of the machinery by hydrolyzing ATP. B. Co-localization of the ESCRT-III component CHMP4A with VPS4A in HeLa cells transiently transfected with exogenous VPS4 ${ }^{\mathrm{WT}}$ or VPS4A ${ }^{\mathrm{EQ}}$. Images were analyzed by confocal microscopy. Scale bar is $10 \mu \mathrm{m}$. C. Localization of VPS4A in transiently transfected cells infected with WT parasites for $24 \mathrm{~h}$. Images were analyzed by confocal microscopy. Scale bar is $5 \mu \mathrm{m}$. D. Growth assay of WT parasites in HeLa cells transiently transfected with exogenous VPS4 ${ }^{\text {WT }}$ or VPS4A ${ }^{\mathrm{EQ}}$ compared to untransfected control. The percentage of PV with 1, 2, 4 or 8+ parasites was calculated for each cell subset. At least 20 PV were counted per blinded sample. Data represents means from 7 biological replicates. E. Mean number of parasites per PV from growth assay. Statistical analysis was by Student's t-test. F. Quantification of ingestion of host cytosolic Venus at $30 \mathrm{mpi}$ in WT (RH) or R $\Delta c p$ I parasites harvest from cells were transiently co-transfected with a plasmid encoding cytosolic Venus fluorescent protein expression and exogenous expression of either VPS4A ${ }^{W T}$ or VPS4A ${ }^{D N}$. G.

Quantification of host cytosolic Venus ingestion at $24 \mathrm{hpi}$. At least 200 parasites were analyzed per blinded sample. Data represents the mean from $\geq 3$ biological replicates. Statistical analysis was by Student's t-test. Only statistical differences are shown. ${ }^{*} p<0.05,{ }^{* *} p<0.01$. 


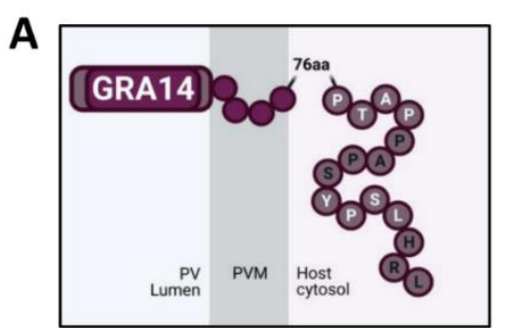

B

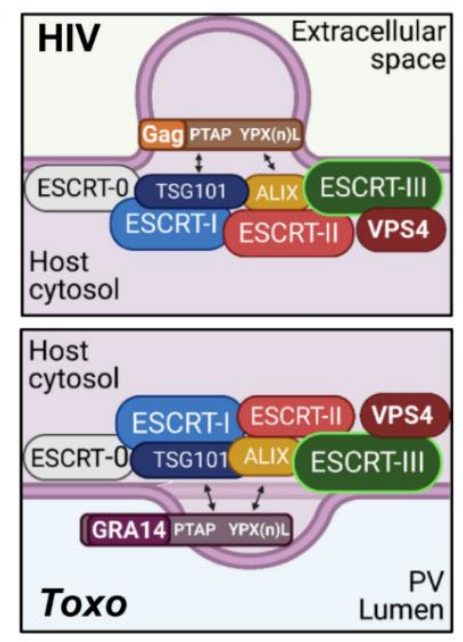

C

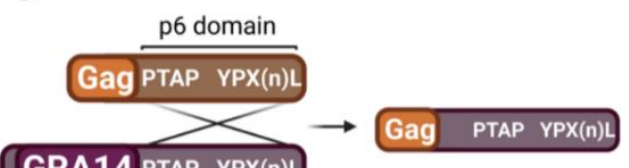

GRA14 PTAP YPX(n)L

C-terminus

D

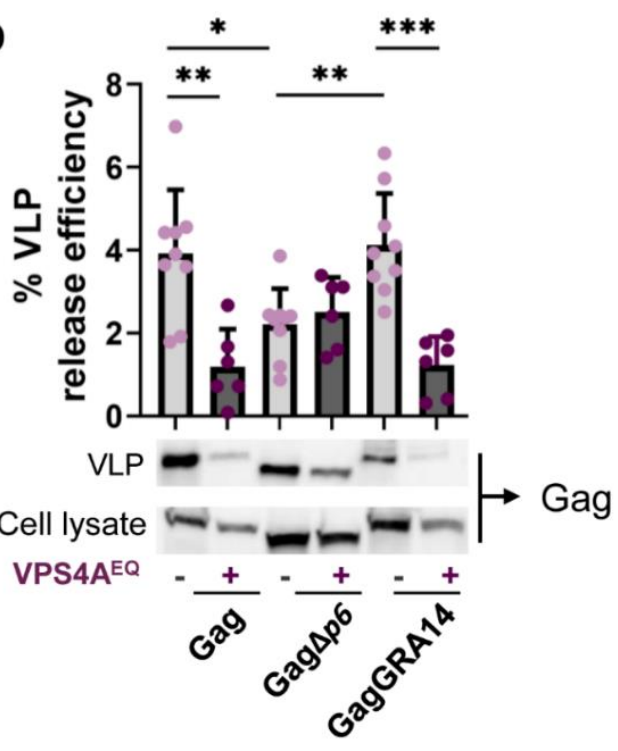

Figure 2. The GRA14 C-terminal domain facilitates ESCRT-dependent release of VLPs

A. Schematic of TgGRA14 topology at the PVM. The TgGRA14 C-terminus encoding the late domain motifs PTAP and $\mathrm{YPX}_{(\mathrm{n})} \mathrm{L}$ is exposed to the host cytosol whereas the $\mathrm{N}$-terminus is exposed to the PV lumen. B. Schematic representation of the predicted recruitment of the ESCRT recruitment by TgGRA14 through the late domain motifs in comparison with their known function in HIV-1 budding. The PTAP and YPX $(n)$ L motifs can mediate interactions with host ESCRT-I components TSG101 and the ESCRT accessory protein ALIX, respectively. C. Experimental design for the substitution of the HIV Gag p6 domain for the TgGRA14 C-terminus portion encoding late domain motifs to generate the GagGRA14. D. Analysis of VLP release by HIV-1 Gag, Gag $\Delta p 6$ and GagGRA14. The role for the ESCRT machinery in GagGRA14 release was assessed by disruption of the ESCRT machinery using the VPS4A dominant negative form (VPS4A ${ }^{\mathrm{EQ}}$ ). Data represents the mean from $\geq 3$ biological 
bioRxiv preprint doi: https://doi.org/10.1101/2021.07.21.453261; this version posted July 21, 2021. The copyright holder for this preprint (which was not certified by peer review) is the author/funder, who has granted bioRxiv a license to display the preprint in perpetuity. It is made available under aCC-BY-NC 4.0 International license.

replicates. Statistical analysis was by Student's t-test. Only statistical differences are shown. ${ }^{*} p<0.05$, ${ }^{* *} p<0.01,{ }^{* \star *} p<0.001$. 
A
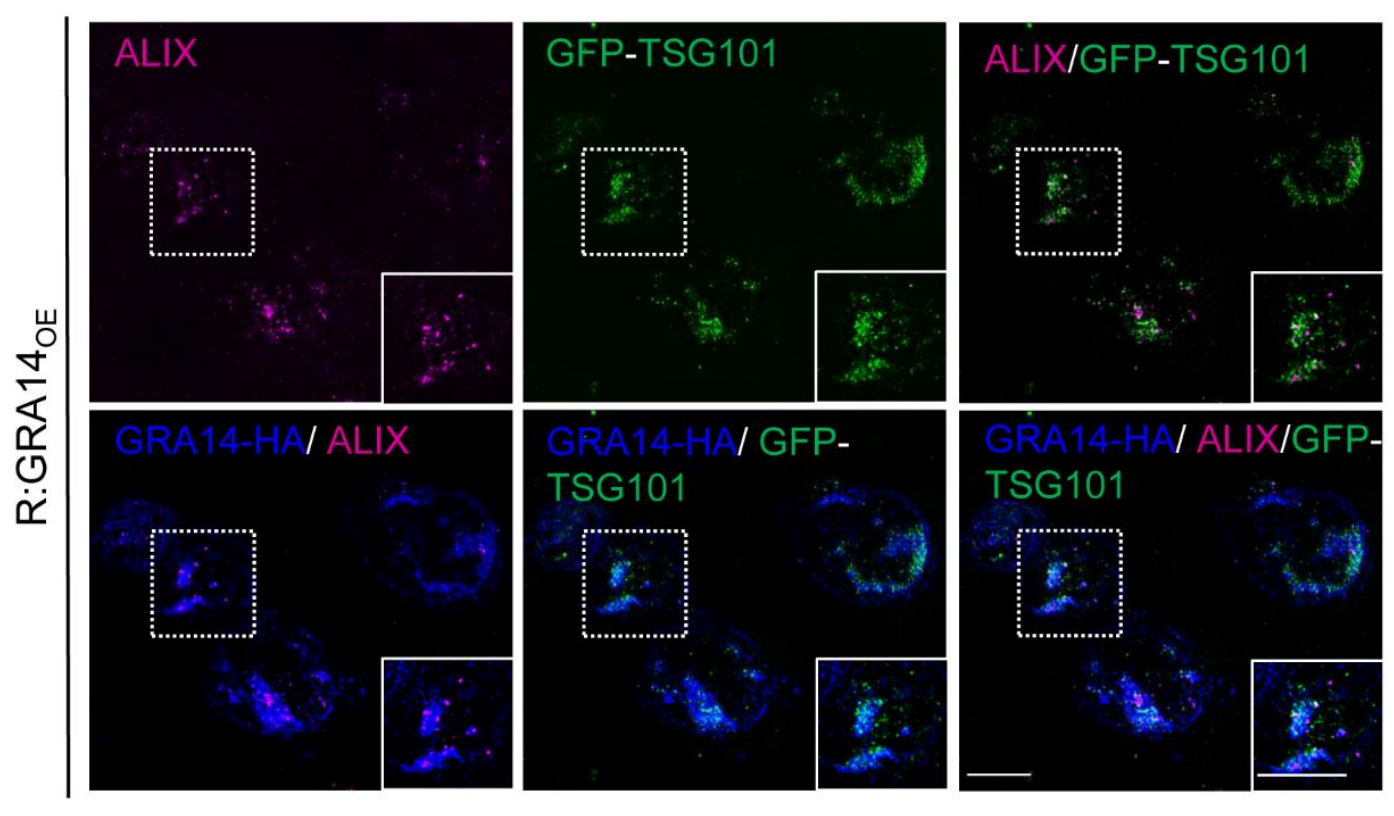

B

C

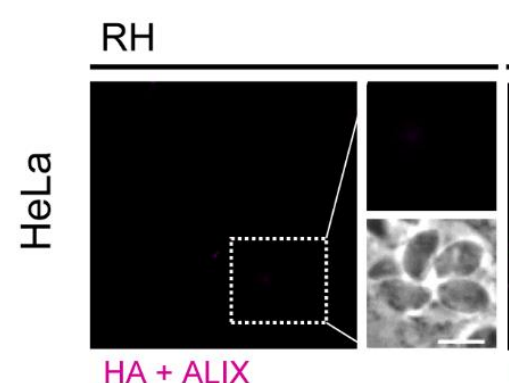

R:GRA14 $\mathrm{OE}$

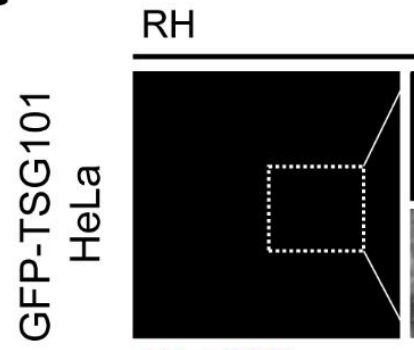

$H A+G F P$

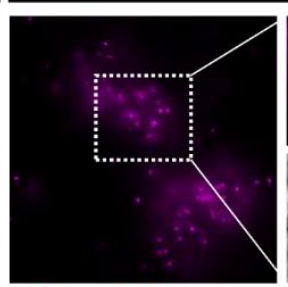

HA + ALIX

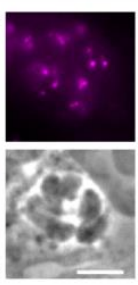

$\mathrm{R}: \mathrm{GRA} 14_{\mathrm{OE}}$

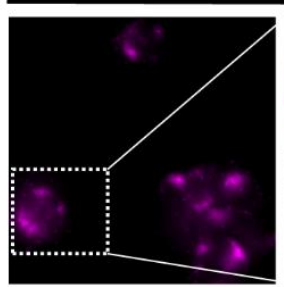

HA + GFP
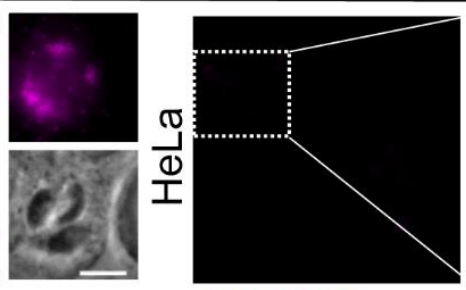

$H A+G F P$

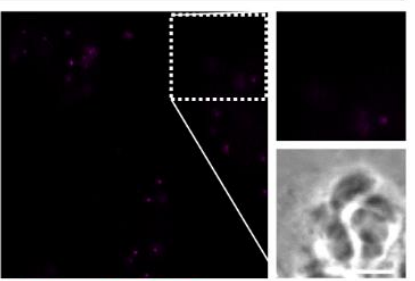

HA + MAPK7

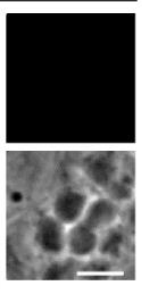

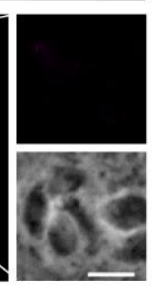


Ligation assay (PLA) reaction from samples infected with either WT or R:GRA140E strains. PLA reactions were performed using antibodies for the host ALIX and the HA-tag to analyze the interaction of TgGRA14 with ALIX. PLA reaction using antibodies against host MAPK7 and HA-tag, was used a negative control. Representative images from at least 3 biological replicates. Scale bar is $5 \mu$ m. C. PLA reaction from GFP-TSG101 HeLa infected with either WT or TgGRA14-HA strains. PLA reactions were performed using antibodies for GFP and the HA-tag to analyze the interaction of TgGRA14 with TSG101. PLA reaction using antibodies against GFP and the HA-tag in WT HeLa cells was used a negative control. Representative images from at least 3 biological replicates. Scale bar is $5 \mu \mathrm{m}$. 


\section{A $\mathrm{RH}$}
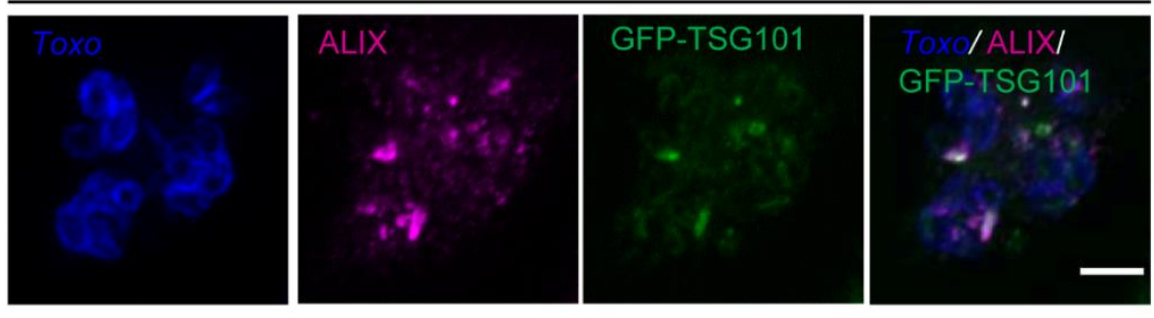

\section{$\mathrm{R} \Delta \mathrm{gra14}$}
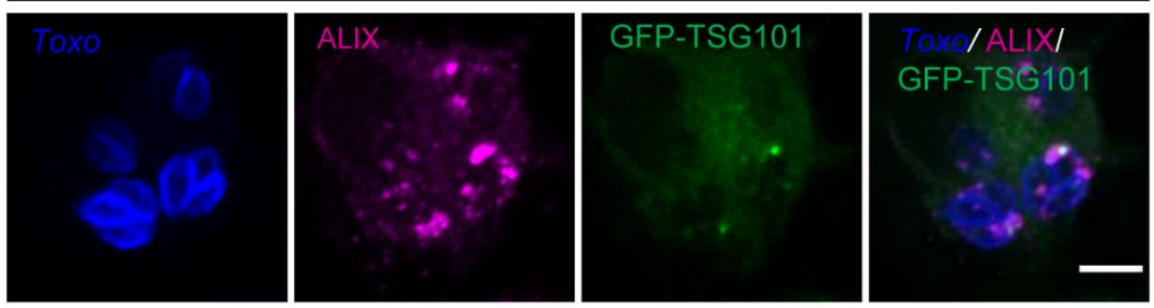

C

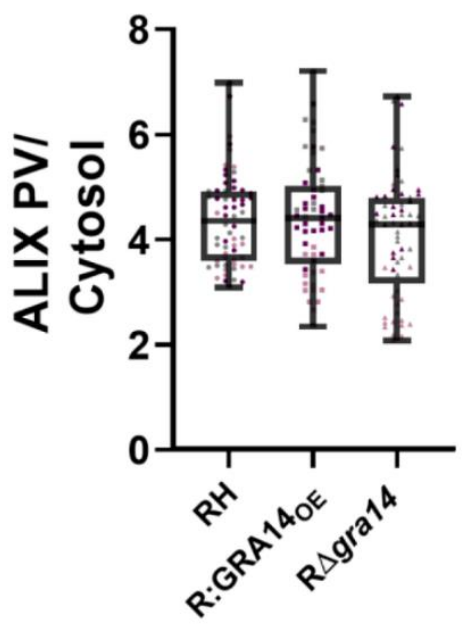

D

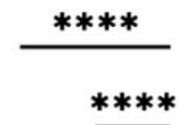

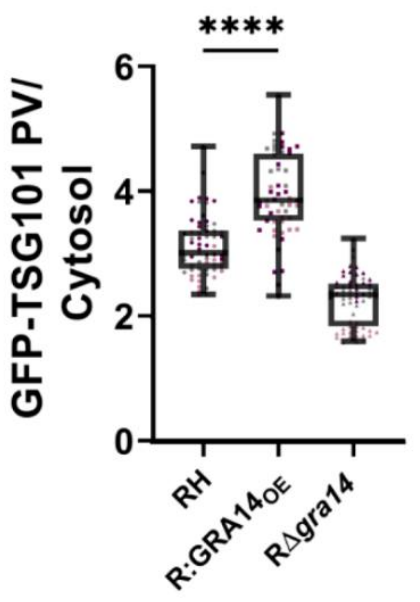

Figure 4. TgGRA14 influences recruitment of GFP-TSG101 to the PV but not association of ALIX with the PV

A. Representative images from three biological replicates comparing the recruitment of ALIX between WT, $\Delta$ gra14 and R:GRA14 $\mathrm{OE}$ strains. B. Representative images from three biological replicates for the GFP-TSG101 recruitment in WT, $\Delta$ gra14 and R:GRA14OE strains. Images were analyzed by confocal 
microscopy. Scale bar is $5 \mu \mathrm{m}$. C. Quantification of ALIX recruitment to the PV between RH, R $\Delta g r a 14$, R:GRA14OE. Data represent the mean ALIX intensity at the PV relative to the cytosol (PV/cytosol). Each point represents the well average. $(\sim 18$ wells per biological replicates $(n=3))$. D. Quantification of TSG101 recruitment to the PV between $\mathrm{RH}, \mathrm{R} \Delta$ gra14, R:GRA14oE parasites. Data represent the mean TSG101 intensity in the PV relative to the cytosol (PV/cytosol). Each point represents the well average. ( 18 wells per biological replicates $(n=3))$. Statistical analysis was done using Kruskal-Wallis test. Only statistical differences are shown. ${ }^{\star \star \star *} p<0.0001$. 

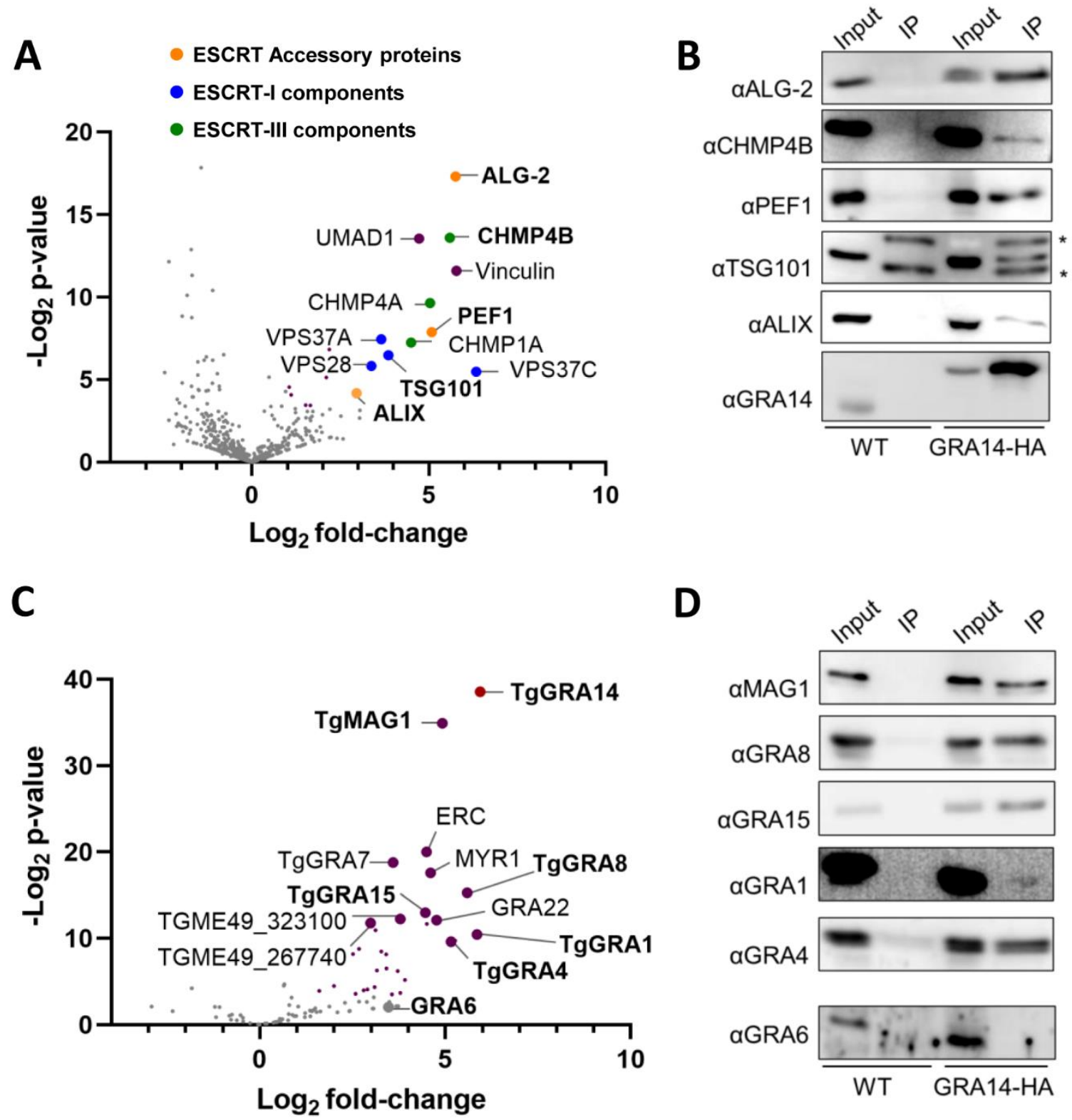

Figure 5. Host ESCRT components immunoprecipitated with TgGRA14

A. Volcano plot of the host proteins immunoprecipitated with TgGRA14 under tachyzoite infection conditions showing the ESCRT-accessory proteins (orange), ESCRT-I components (blue), ESCRT-III components (green) and other non-ESCRT associated proteins (purple). Colored dots represent 
proteins with $>1 \log 2$ fold change in tagged vs control lysates and a negative log2 $p$-value $>3.32$

(equivalent to $\mathrm{p}<0.1$ ). B. Immunoblots for the analysis of immunoprecipitation samples confirming the TgGRA14 interaction with host ESCRT components. C. Volcano plot representative of the T. gondii proteins immunoprecipitated with TgGRA14. Some of the enriched dense granule proteins are highlighted in purple. Colored dots represent proteins with $>1 \log 2$ fold change in tagged vs control lysates and a negative $\log 2 p$-value $>3.32$ (equivalent to $p<0.1$ ). D. Immunoblot analysis of immunoprecipitation samples confirming the TgGRA14 interaction with some of the enriched dense granule proteins. 


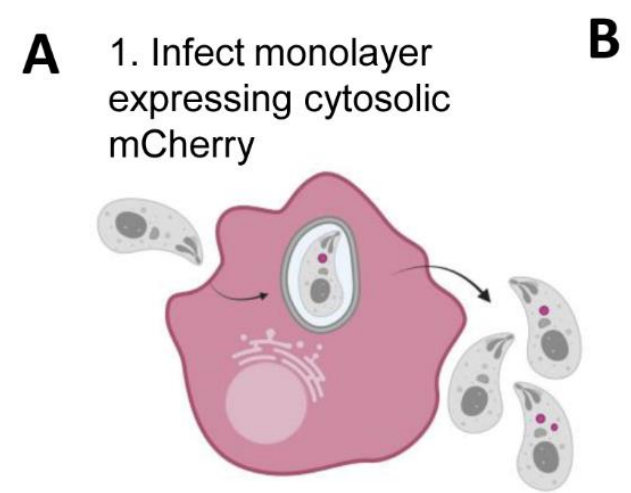

2. At 4 hpi add LHVS

3. Harvest parasites at $24 \mathrm{hpi}$
B

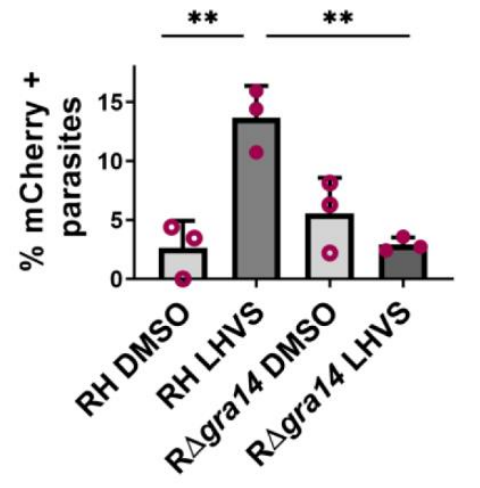

C

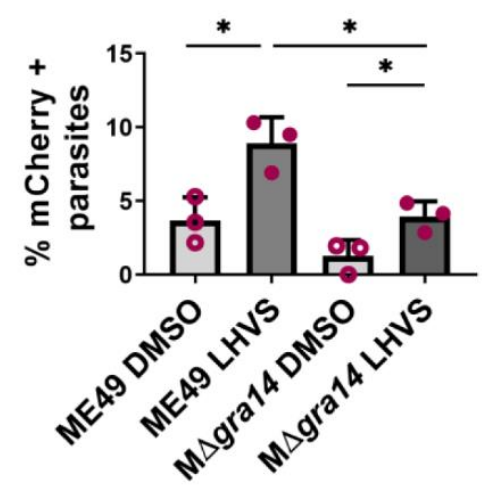

Figure 6. Replicating parasites deficient of TgGRA14 do not internalize host cytosolic proteins as efficiently as wildtype

A. Experimental design for the analysis of the internalization of host cytosolic proteins of TgGRA14deficient parasites. (1) Inducible mCherry HeLa cells were infected with parasites for 4 hours, (2) at 4 hpi, extracellular parasites were removed, and the infected monolayer was treated with LHVS for $20 \mathrm{~h}$, (3) parasites were harvested at $24 \mathrm{hpi}$ and analyzed by microscopy. B. Quantification of host cytosolic mCherry uptake at 24 hpi by WT or R $\Delta$ gra14 type I strains treated with DMSO or LHVS for $20 \mathrm{~h}$. C. Quantification of host cytosolic mCherry uptake at 24 hpi by WT or M $\Delta$ gra 14 type II strains treated with DMSO or LHVS for $20 \mathrm{~h}$. At least 200 parasites were analyzed per blinded sample. Data represents the mean from $\geq 3$ biological replicates. Statistical analysis was by Student's t-test. Only statistical differences are shown. ${ }^{\star} p<0.05,{ }^{* *} p<0.01,{ }^{* \star *} p<0.001$. 

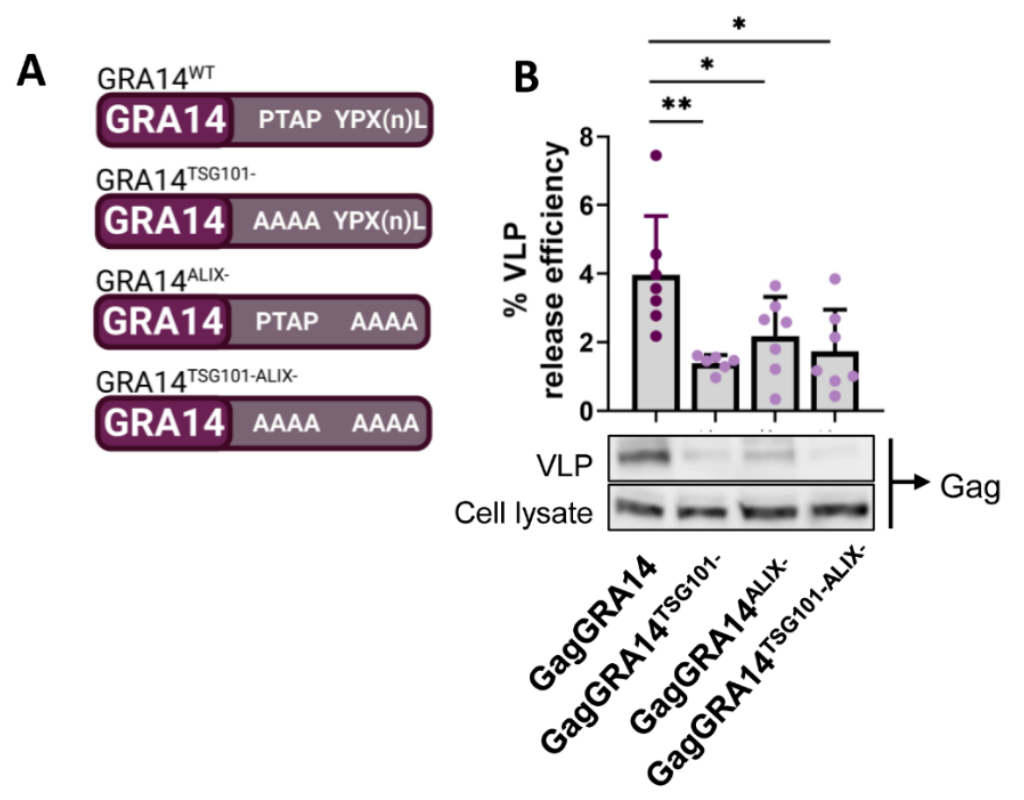

Figure 7. Late domain motifs encoded in TgGRA14 C-terminus can mediate ESCRT-dependent HIV virus-like particle release

A. Schematic of the generation of mutants in the late domain motifs PTAP and YPX $(n)$ encoded by TgGRA14. B. Analysis of virus-like particle release by GagGRA14 and GagGRA14 mutants. Data represents the mean from $\geq 3$ biological replicates. Statistical analysis was by Student's t-test. Only statistical differences are shown. ${ }^{*} p<0.05,{ }^{* *} p<0.01,{ }^{* * *} p<0.001$. 
A
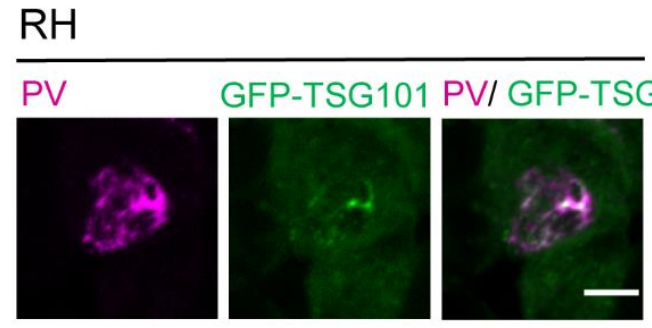

\section{$\mathrm{R} \Delta$ gra14}
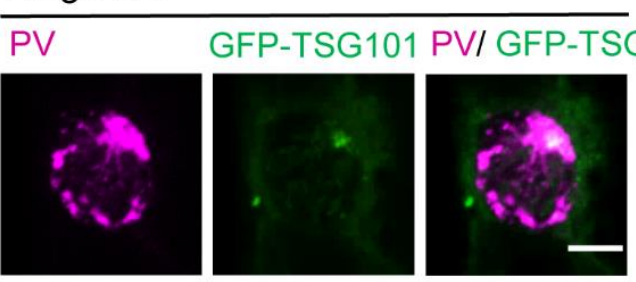

$\mathrm{R} \Delta$ gra14GRA14WT
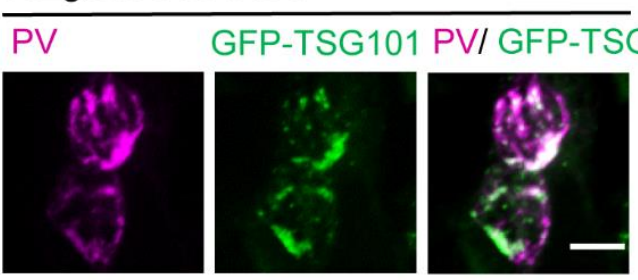

B

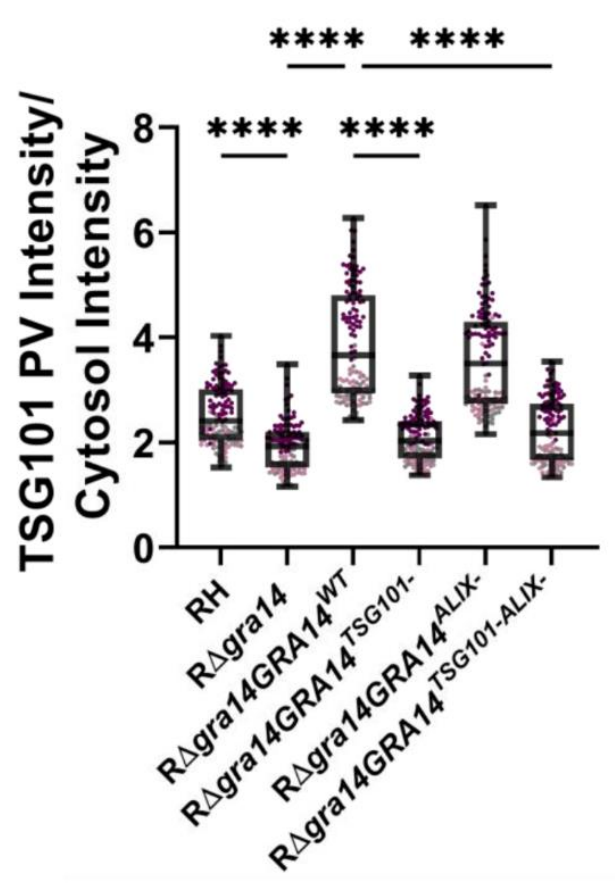

RAgra14GRA14TSG101-

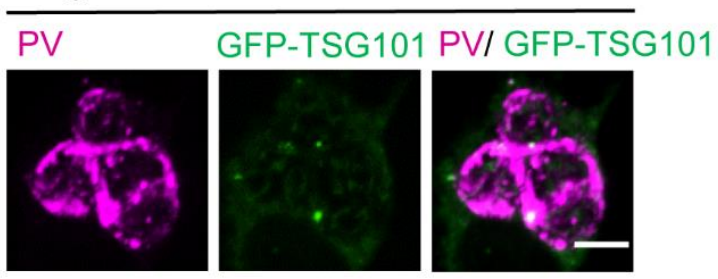

RAgra14GRA14ALIX-

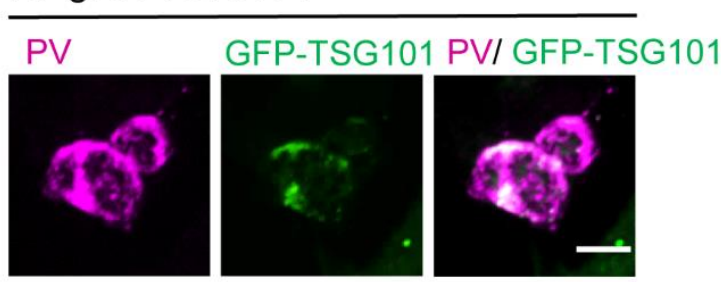

$\mathrm{R} \Delta$ gra14GRA14 ${ }^{\mathrm{TSG} 101-A L I X-}$

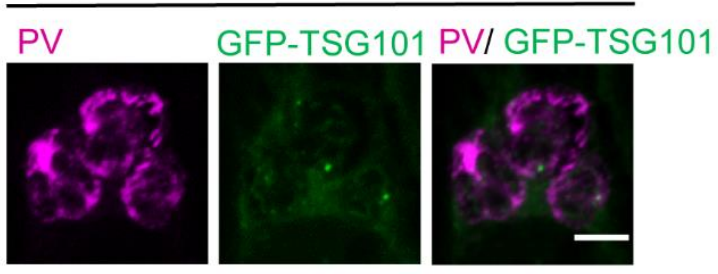

C DMSO LhVS

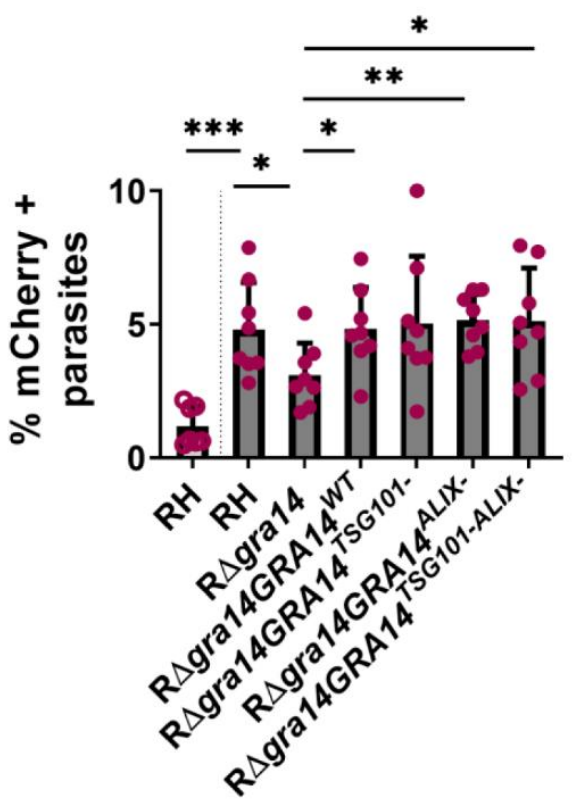


Figure 8. TgGRA14 PTAP late domain motif is necessary for GFP-TSG101 recruitment but not for uptake of host cytosolic proteins

A. Representative images from 3 biological replicates for the GFP-TSG101 recruitment in RAgra14GRA14 complemented strains. Images were analyzed by confocal microscopy. Scale bar is 5 $\mu \mathrm{m}$. B. Quantification of TSG101 recruitment to the PV between WT, R $\Delta$ gra14 and R $\Delta g r a 14$ complementation mutants. Data represent the mean TSG101 intensity in the PV relative to the cytosol (PV/cytosol). Each point represents the well average. ( 18 wells per biological replicates $(n=3))$.

Statistical analysis was done using Kruskal-Wallis test. Only statistical differences are shown. ${ }^{* * * *} p<0.0001$. C. Quantification of host cytosolic mCherry uptake by R $\Delta$ gra 14 and $\mathrm{R} \Delta$ gra $14 G R A 14$ mutants treated with LHVS for $20 \mathrm{~h}$. At least 200 parasites were analyzed per blinded sample. Data represents the mean from $\geq 3$ biological replicates. Statistical analysis was by Student's t-test. 


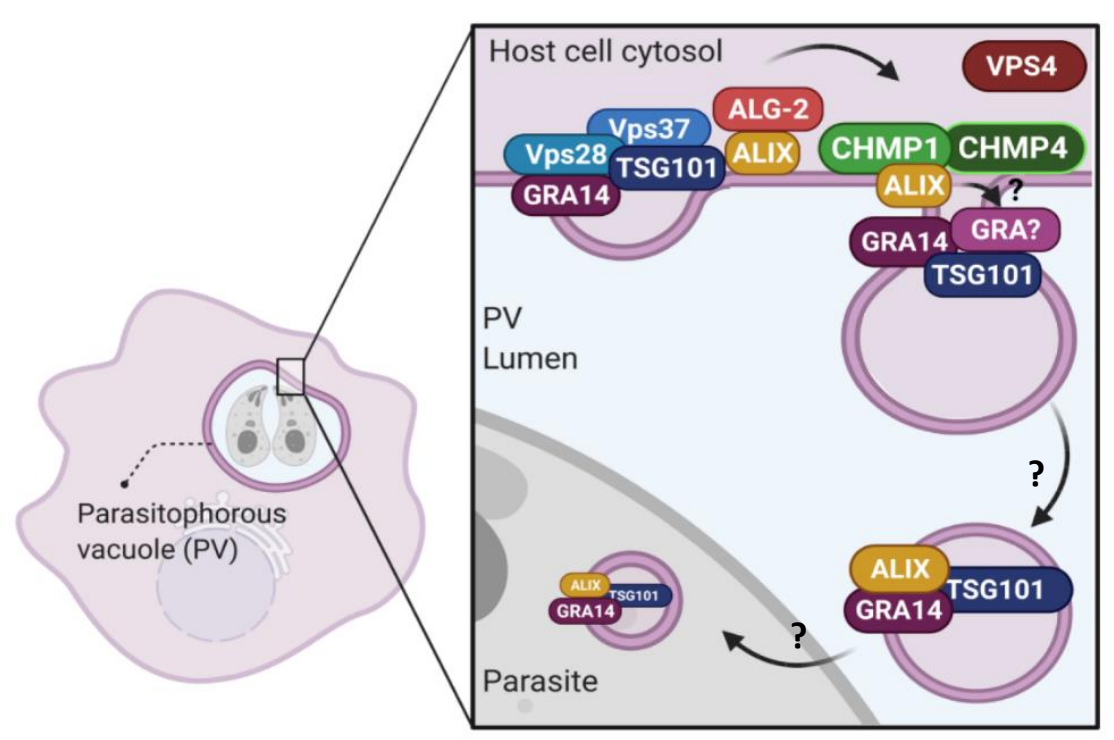

Figure 9. Model of TgGRA14-ESCRT interactions for the uptake of host cytosolic proteins

Our data supports a model for the interaction of TgGRA14 with the host ESCRT machinery at the PVM for the uptake of host cytosolic proteins. We hypothesize that through this interaction, vesicles packaging host cytosolic proteins are formed at the PVM and are further endocytosed by the parasites by an unknown mechanism. ESCRT components like TSG101 and ALIX could potentially be packaged within these vesicles resembling what occurs in ESCRT-dependent exosome formation. Furthermore, other transmembrane or soluble dense granule proteins are likely contributing to this pathway. 


\section{Supplemental Figures, Tables, and Data}
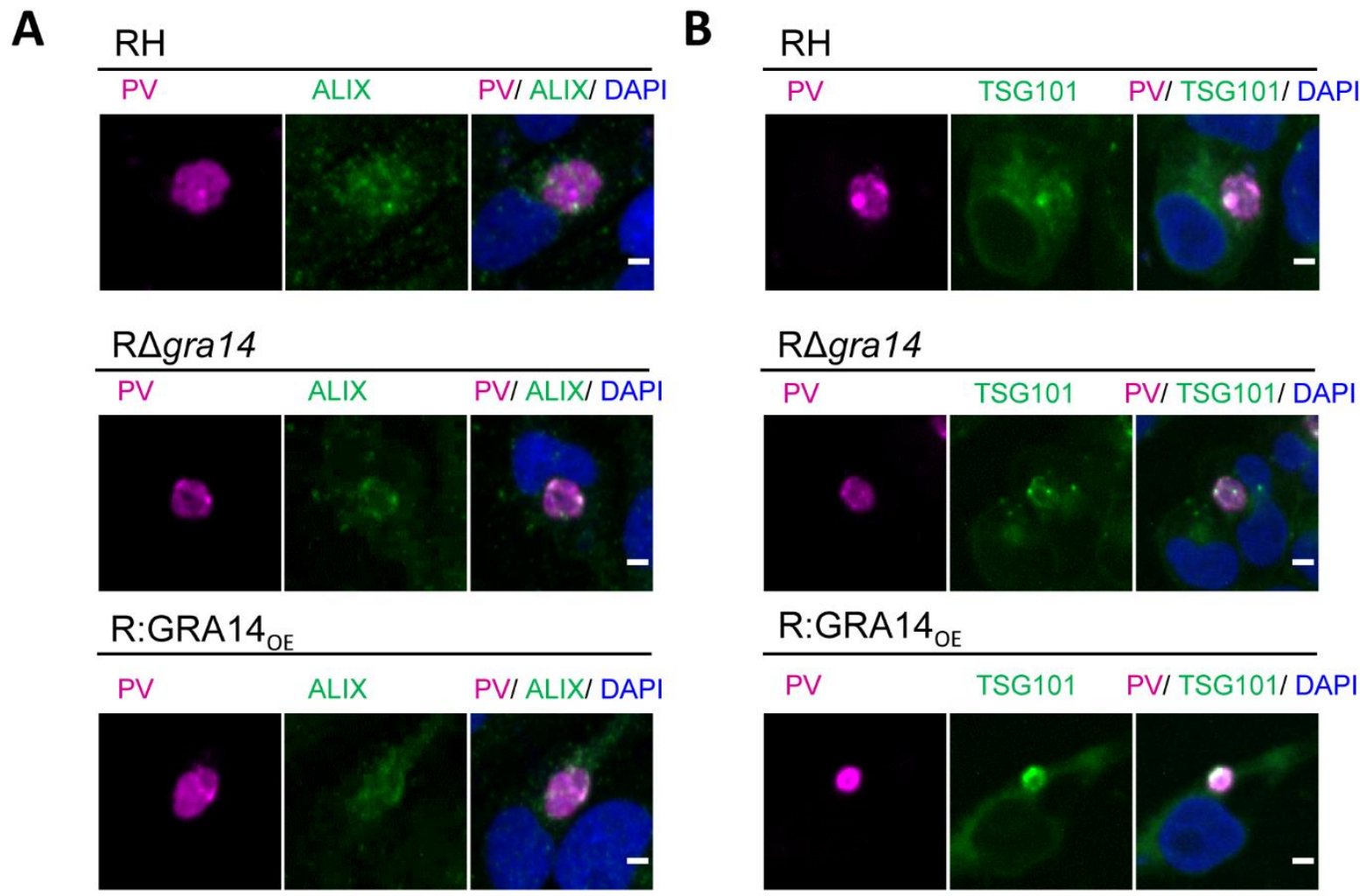

Figure S1. Comparison of ALIX and GFP-TSG101 recruitment to the PVM

A. Representative images for segmentation and quantification of GFP-TSG101 and ALIX to the PVM between WT, R $\Delta$ gra14 and R:GRA14 $\mathrm{OE}$. Scale bar is $5 \mu \mathrm{m}$. 
A
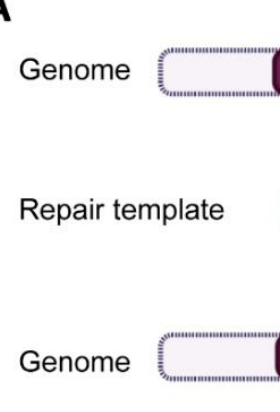

GRA14
B

\section{GRA14}

\section{HA}

P9

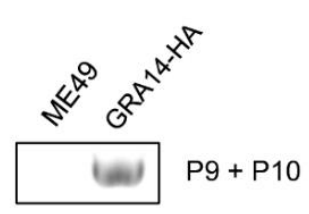

HA

P10

C WT
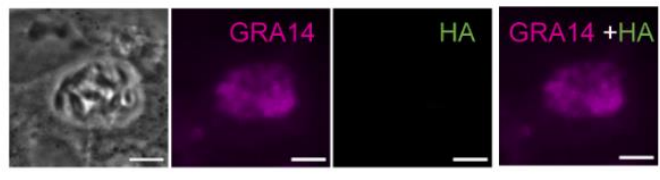

GRA14-HA
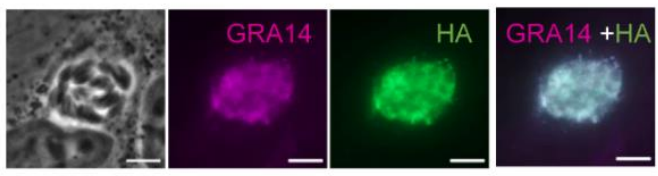

Figure S2. Endogenous C-terminal tagging of TgGRA14 in a type II strain

A. Schematic for the tagging strategy with primer amplification sites. B. PCR to validate the tagging of TgGRA14 with HA in the ME49 $\Delta k u 80$ background. C. Representative images showing the colocalization of HA with TgGRA14 in the tagged strain. Scale bar is $5 \mu \mathrm{m}$. 


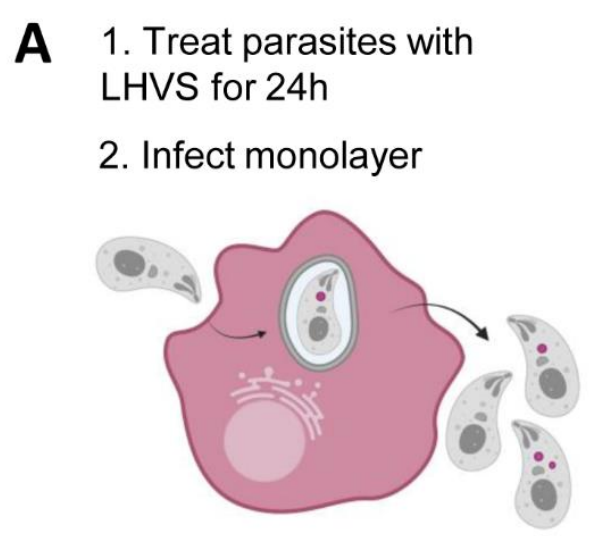

3. Harvest parasites at $4 \mathrm{hpi}$

\section{B}

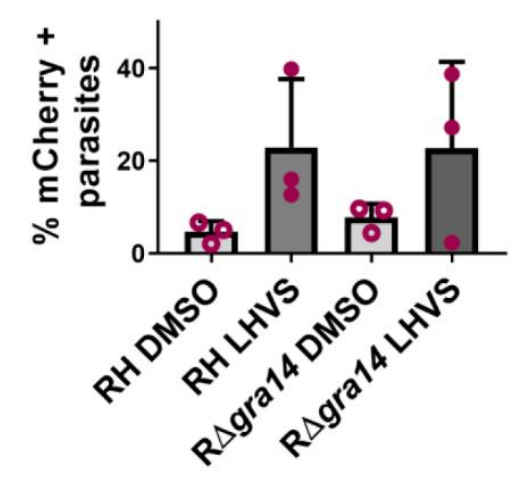

Figure S3. TgGRA14 is not needed for the internalization of host cytosolic proteins early in infection

A. Experimental design for the analysis of the internalization of host cytosolic proteins of TgGRA14deficient parasites. (1) Parasites were treated with $5 \mu \mathrm{M}$ LHVS for $24 \mathrm{~h}$ prior to infection, (2) inducible mCherry HeLa cells were infected with parasites for $4 \mathrm{~h}$, (3) the parasites were harvested at 4 hpi and analyzed by microscopy. B. Quantification of host cytosolic mCherry uptake at 4 hpi by WT or R $\Delta$ gra14 type I strains treated with DMSO or LHVS for $24 \mathrm{~h}$. At least 200 parasites were analyzed per blinded sample. Data represents the mean from $\geq 3$ biological replicates. Statistical analysis was by Student's $t-$ test. Only statistical differences are shown. 
A

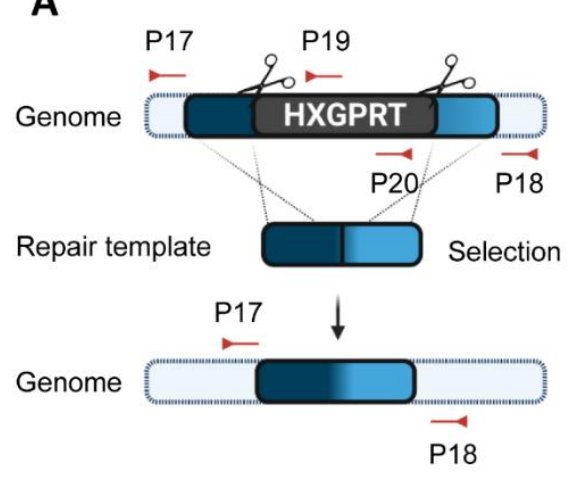

C

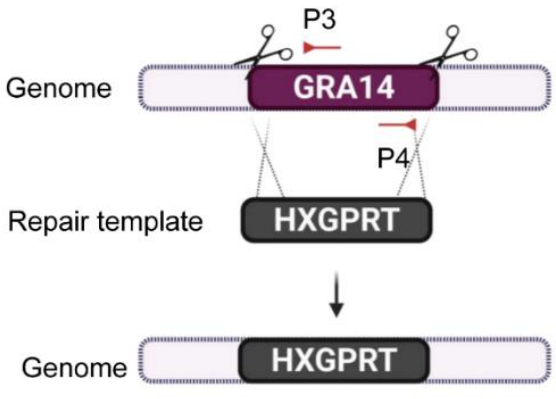

B

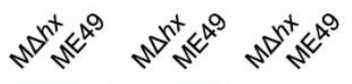
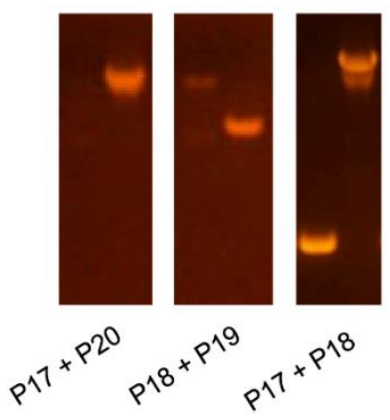

D

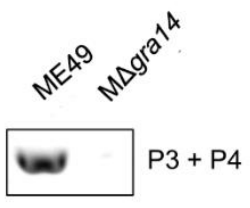

$\mathbf{E}$

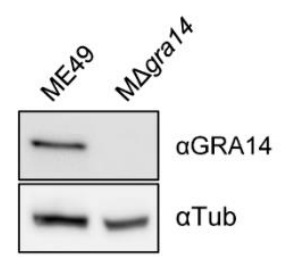

\section{Figure S4. Deletion of TgGRA14 in type II strain}

A. Schematic for the deletion of the HXGPRT gene with primer amplification sites B. PCR to validate the deletion of HXGPRT. C. Schematic for the deletion of the TgGRA14 with primer amplification sites.

D. PCR to validate the deletion of TgGRA14 in the ME49 $\Delta$ ku80 background. E. Immunoblot confirming the deletion of TgGRA14 in the MAgra14 strain. 
A

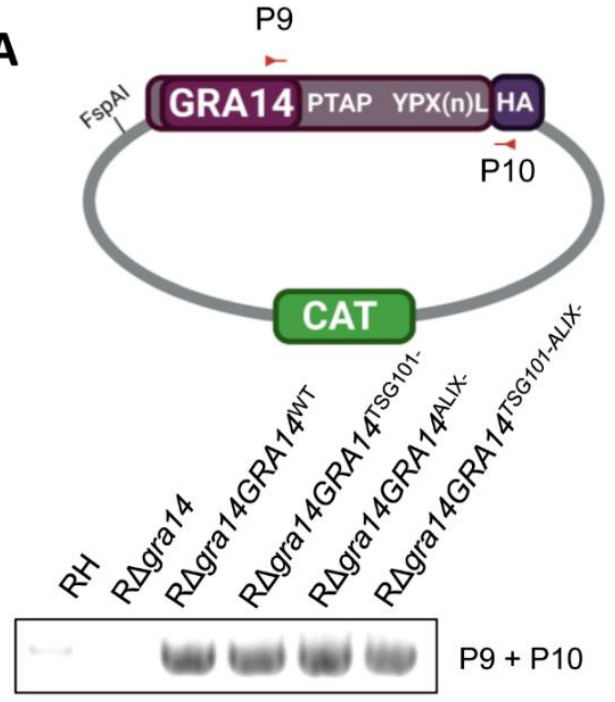

B

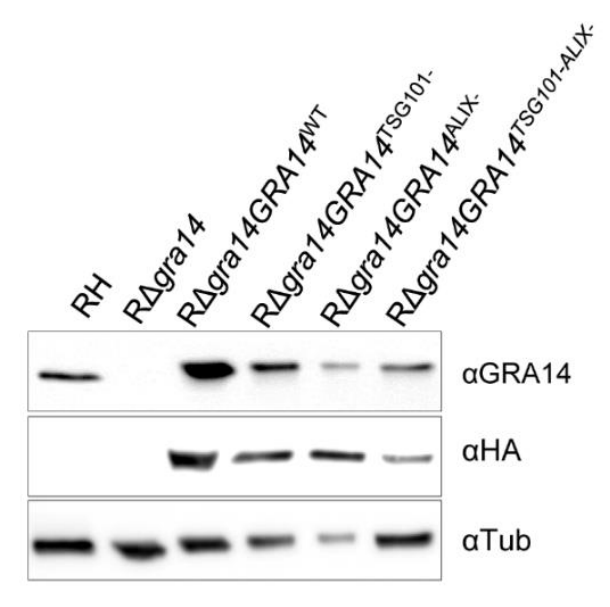

C
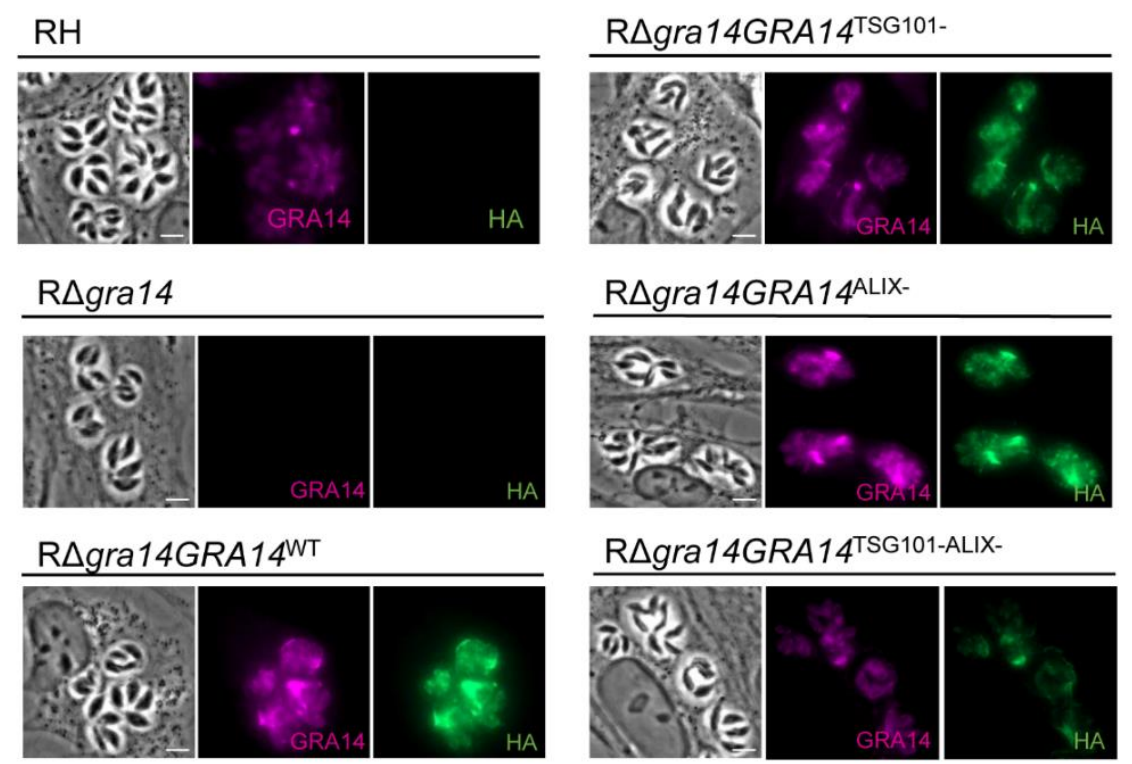

\section{Figure S5. RAgra14:gra14-HA complementation mutants}

A. Schematic representation of the plasmids generated for TgGRA14 complementation. PCR to validate the presence of TgGRA14-HA in the RAgra14GRA14 complementation mutants. B. Immunoblot confirming the presence of TgGRA4 and HA in the RAgra14GRA14 complementation mutants. C. Representative images showing the presence of HA and GRA14 in the RAgra14GRA14 complementation mutants. Scale bar is $5 \mu \mathrm{m}$. 

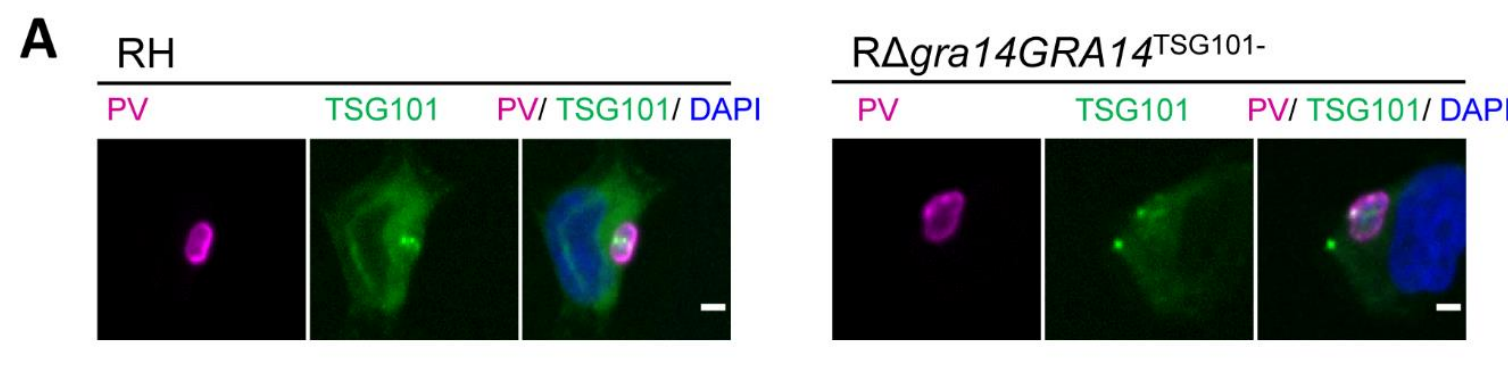

R $\Delta$ gra14

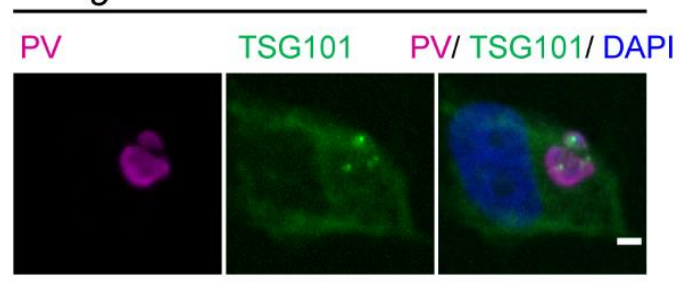

\begin{tabular}{lll} 
RAgra14GRA14 ALIX- \\
\hline PV & TSG101 PVI TSG101/ DAPI
\end{tabular}

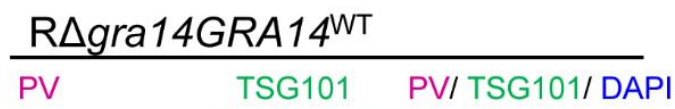
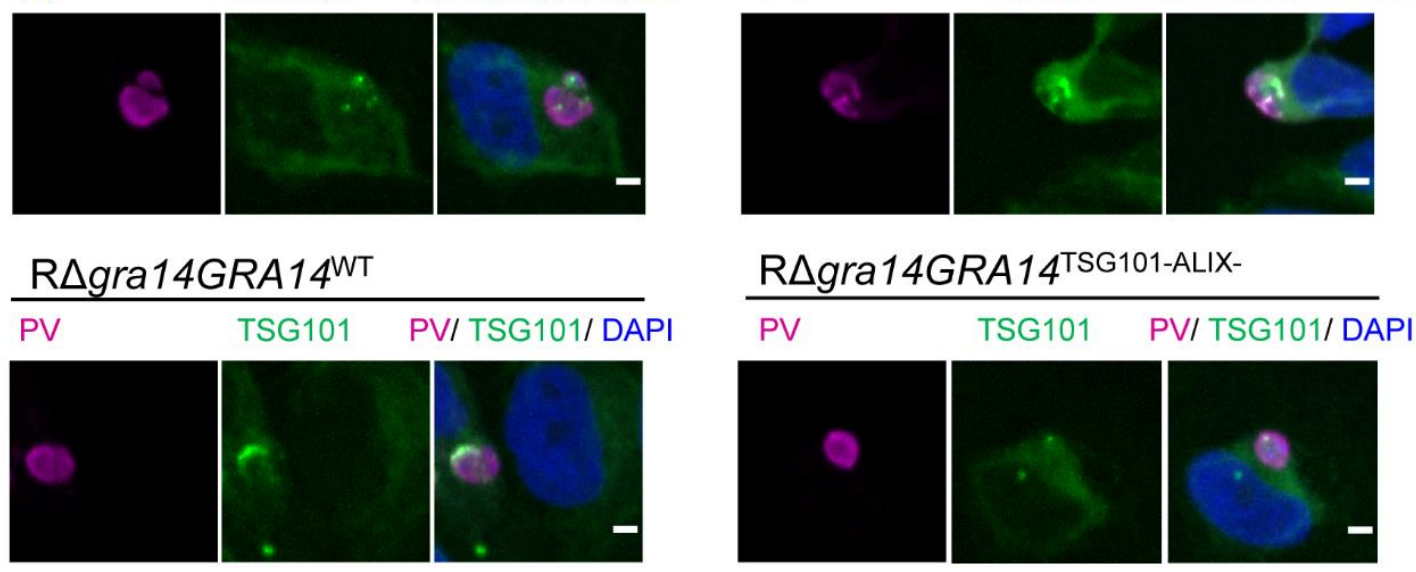

Figure S6. Comparison of GFP-TSG101 recruitment to the PVM following disruption of late

\section{domain motifs}

A. Representative images for segmentation and quantification of GFP-TSG101 to the PVM between WT, R $\Delta$ gra14 and R $\Delta$ gra14 complement strains. Scale bar is $5 \mu \mathrm{m}$. 
bioRxiv preprint doi: https://doi.org/10.1101/2021.07.21.453261; this version posted July 21, 2021. The copyright holder for this preprint (which

was not certified by peer review) is the author/funder, who has granted bioRxiv a license to display the preprint in perpetuity. It is made available under aCC-BY-NC 4.0 International license.

\section{Supplementary Dataset 1: LC-MS/MS Analysis}

Data are presented in 9 different tabs. The "Results Summary" tab provides an overview and heat map of the top protein hits identified for each of the three different conditions (Tz-HFF: tachyzoite fibroblast infection; Bz-HFF: bradyzoite fibroblast infection; Neuron: neuron infection). The tabs labeled "Condition_PeptideCalc" demonstrate the analysis pipeline, including equations used in Excel to ultimately calculate $\log _{2}$ protein fold changes and p-values. The tabs labeled "Condition_VolcanoPlot" provide a graphical overview of protein fold changes and short names for the top protein hits. Lastly, the "Peptide_RawData" tabs provide identification scores and PEP values for each unique peptide identified from either Toxoplasma-Human or Toxoplasma-Mouse combined proteome database searches. 
Table S1: T. gondii proteins encoding a P(S/T)AP motif identified bioinformatically

\begin{tabular}{|c|c|c|}
\hline Gene ID & Product Description & $\begin{array}{l}\text { Top Predicted Location } \\
\text { (TAGM-MCMC) }\end{array}$ \\
\hline TGME49_239740 & Dense granule protein GRA14 & dense granules \\
\hline TGME49_201180 & hypothetical protein & dense granules \\
\hline TGME49_231960 & Omega secalin, putative & dense granules \\
\hline TGME49_311470 & Rhoptry neck protein RON5 & rhoptries 1 \\
\hline TGME49_203990 & Rhoptry protein ROP12 & rhoptries 1 \\
\hline TGME49_312270 & Rhoptry protein ROP13 & rhoptries 1 \\
\hline TGME49_245490 & Microneme protein MIC8 & micronemes \\
\hline TGME49_287040 & hypothetical protein & micronemes \\
\hline TGME49_245510 & $\begin{array}{l}\text { Phospholipid-translocating P-type ATPase, flippase } \\
\text { subfamily protein }\end{array}$ & Golgi \\
\hline TGME49_310350 & GPI inositol-deacylase & $\begin{array}{l}\text { Mitochondrion- } \\
\text { membranes } \\
\end{array}$ \\
\hline $\begin{array}{l}\text { TGME49_248510 } \\
\text { TGME49_265240 }\end{array}$ & $\begin{array}{l}\text { hypothetical protein } \\
\text { hypothetical protein }\end{array}$ & $\begin{array}{l}\text { nucleolus } \\
\text { Nucleus- } \\
\text { chromatin }\end{array}$ \\
\hline TGME49_201660 & hypothetical protein & null \\
\hline TGME49_201730 & hypothetical protein & null \\
\hline TGME49_207740 & hypothetical protein & null \\
\hline TGME49_209620 & Peptidase A1 domain-containing protein & null \\
\hline TGME49_211320 & hypothetical protein & null \\
\hline TGME49_217420 & hypothetical protein & null \\
\hline TGME49_243160 & Toxoplasma gondii family A protein & null \\
\hline TGME49_245770 & hypothetical protein & null \\
\hline TGME49_250670 & hypothetical protein & null \\
\hline TGME49_254790 & hypothetical protein & null \\
\hline TGME49_258840 & hypothetical protein & null \\
\hline TGME49_274110 & Glycoprotease family protein & null \\
\hline TGME49_295935 & KRUF family protein & null \\
\hline TGME49_300320 & rRNA adenine N(6)-methyltransferase & null \\
\hline TGME49_313120 & RPOLD domain-containing protein & null \\
\hline TGME49_313630 & hypothetical protein & null \\
\hline TGME49_315360 & INCENP_ARK-bind domain-containing protein & null \\
\hline
\end{tabular}




\begin{tabular}{l|l|l|} 
TGME49_315958 & Radical SAM domain-containing protein & null \\
TGME49_318500 & Cpw-wpc domain-containing protein & null \\
TGME49_320260 & hypothetical protein & null \\
TGME49_320540 & hypothetical protein & null \\
\hline
\end{tabular}

Identification of Toxoplasma gondii effector proteins encoding a putative P(S/T)AP motif and a signal peptide as potential candidate interactors with the host ESCRT-I component, TSG101. Bioinformatic search was performed using the vEuPathDB Toxoplasma Informatics Resources Database (ToxoDB) and their predicted localization is based on the hyperplexed localization of organelle proteins by isotype tagging (hyperLOPIT) data set ${ }^{34}$. 
Table S2A: Host proteins significantly enriched following immunoprecipitation with GRA14-HA

\begin{tabular}{|c|c|c|c|c|c|}
\hline \multirow[t]{2}{*}{$\begin{array}{l}\text { Host enriched } \\
\text { proteins }\end{array}$} & \multirow{2}{*}{\multicolumn{2}{|c|}{ Uniprot ID }} & \multicolumn{3}{|c|}{ Log2 Fold Change } \\
\hline & & & Tz-HFF & Bz-HFF & Tz-Neuron \\
\hline VPS37C & A5D8V6 & ESCRT-I & 6.34 & 4.82 & 2.25 \\
\hline Vinculin & P18206 & $\begin{array}{l}\text { Actin-filament binding } \\
\text { protein }\end{array}$ & 5.78 & 1.57 & Not detected \\
\hline PDCD6 & 075340 & Adaptor protein & 5.75 & 5.58 & 6.36 \\
\hline CHMP4B & Q9H444 & ESCRT-III & 5.59 & 2.73 & 1.45 \\
\hline PEF1 & Q9UBV8 & $\begin{array}{l}\text { ALG-2 interacting } \\
\text { protein }\end{array}$ & 5.08 & 3.79 & 0.00 \\
\hline CHMP4A & Q9BY43 & ESCRT-I & 5.03 & 1.11 & 0.00 \\
\hline UMAD1 & C9J7I0 & $\begin{array}{l}\text { UBPA1-MVB12- } \\
\text { associated (UMA) } \\
\text { domain containing } 1\end{array}$ & 4.73 & 3.22 & 0.00 \\
\hline CHMP1A & Q9HD42 & ESCRT-I & 4.50 & 1.31 & 0.00 \\
\hline TSG101 & Q99816 & ESCRT-III & 3.86 & 2.49 & 0.00 \\
\hline VPS37A & Q8NEZ2 & ESCRT-I & 3.66 & 1.37 & 0.00 \\
\hline VPS28 & Q9UK41 & ESCRT-III & 3.38 & 2.48 & 2.64 \\
\hline ALIX & Q8WUM4 & Accessory protein & 2.96 & 0.94 & 0.00 \\
\hline
\end{tabular}


Table S2B: T. gondii proteins significantly enriched following immunoprecipitation with GRA14-

HA

\begin{tabular}{|c|c|c|c|c|}
\hline \multirow[t]{2}{*}{$\begin{array}{l}\text { T. gondii enriched } \\
\text { proteins }\end{array}$} & \multirow[t]{2}{*}{ Uniprot ID } & \multicolumn{3}{|c|}{ Log2 Fold Change } \\
\hline & & Tz-HFF & Bz-HFF & Tz-Neuron \\
\hline GRA14 & TGME49_239740 & 5.94 & 3.44 & 4.89 \\
\hline GRA1 & TGME49_270250 & 5.86 & 6.48 & 6.95 \\
\hline GRA8 & TGME49_254720 & 5.59 & 3.45 & 4.09 \\
\hline GRA9 & TGME49_251540 & 5.26 & 4.10 & 3.91 \\
\hline GRA4 & TGME49_310780 & 5.15 & 1.45 & 3.19 \\
\hline MAG1 & TGME49_270240 & 4.92 & 3.72 & 4.47 \\
\hline GRA22 & TGME49_215220 & 4.77 & 1.73 & 0.00 \\
\hline MYR1 & TGME49_254470 & 4.60 & 1.96 & 3.22 \\
\hline Hypothetical & TGME49_206340 & 4.51 & 0.00 & 0.00 \\
\hline ERC & TGME49_229480 & 4.49 & 1.95 & 2.72 \\
\hline GRA15 & TGME49_275470 & 4.47 & 0.60 & 2.13 \\
\hline Hypothetical & TGME49_323100 & 3.79 & 0.00 & 0.00 \\
\hline GRA16 & TGME49_208830 & 3.72 & 0.00 & 0.00 \\
\hline GRA7 & TGME49_203310 & 3.59 & 3.07 & 3.82 \\
\hline Hypothetical & TGME49_267740 & 2.99 & 0.68 & 0.00 \\
\hline
\end{tabular}


Table S3: Strains used in this manuscript

\begin{tabular}{|c|c|c|c|c|c|c|}
\hline Strain & $\begin{array}{l}\text { Parental } \\
\text { strain }\end{array}$ & Genotype & $\begin{array}{l}\text { Selection } \\
\text { marker }\end{array}$ & Selection & Reference & Notes \\
\hline $\mathrm{RH}$ & & $\mathrm{RH}$ & & & & \\
\hline$\Delta c p l$ & $\mathrm{RH}$ & & DHFR & Pyrimethamine & & $\begin{array}{l}\text { Carruthers } \\
\text { lab }\end{array}$ \\
\hline $\begin{array}{l}\text { RH GRA14- } 1 \times \text { HA } \\
\text { (R:GRA14 } \mathrm{OE})\end{array}$ & $\mathrm{RH} \Delta h p t$ & & HPT & $\begin{array}{l}\text { Mycophenolic } \\
\text { acid (MPA) + } \\
\text { Xanthine }\end{array}$ & 26 & $\begin{array}{l}\text { Kindly } \\
\text { provided } \\
\text { by P. } \\
\text { Bradley }\end{array}$ \\
\hline $\mathrm{R} \Delta$ gra14 & $\mathrm{RH} \Delta h p t$ & & HPT & MPA + Xanthine & 26 & $\begin{array}{l}\text { Kindly } \\
\text { provided } \\
\text { by P. } \\
\text { Bradley }\end{array}$ \\
\hline $\mathrm{R} \Delta$ gra14GRA14 ${ }^{W T}$ & $\mathrm{RH} \Delta$ gra14 & $\begin{array}{l}\text { RH } \Delta \text { gra14: } \\
\text { gra14 }{ }^{\mathrm{WT}} \text { - } \\
{ }_{1 \times} H A\end{array}$ & CAT & Chloramphenicol & $\mathrm{TR}^{1}$ & \\
\hline $\mathrm{R} \Delta$ gra14GRA14 ${ }^{\text {TSG101- }}$ & $\mathrm{RH} \Delta$ gra14 & $\begin{array}{l}\text { RH } \Delta \text { gra14: } \\
\text { gra14 } \\
{ }_{-1}{ }^{\mathrm{TSG}} \mathrm{HA}\end{array}$ & CAT & Chloramphenicol & $\mathrm{TR}^{1}$ & \\
\hline $\mathrm{R} \Delta$ gra14GRA14 ${ }^{A L I X-}$ & $\mathrm{RH} \Delta$ gra 14 & $\begin{array}{l}\text { RH } \Delta \text { gra14: } \\
\text { gra14 }{ }^{\text {ALIX-- }} \\
{ }_{1 \times} H A\end{array}$ & CAT & Chloramphenicol & $\mathrm{TR}^{1}$ & \\
\hline $\begin{array}{l}\mathrm{R} \Delta \text { gra14GRA14 } \\
\text { ALIX- }\end{array}$ & $\mathrm{RH} \Delta$ gra14 & $\begin{array}{l}\text { RH } \Delta \text { gra14: } \\
\text { gra14 }{ }^{\text {TSG101- }} \\
{\text { ALIX- }{ }_{-1 X} H A}\end{array}$ & CAT & Chloramphenicol & $\mathrm{TR}^{1}$ & \\
\hline ME49 $\Delta k u 80$ & ME49 & $\Delta k u 80$ & none & none & 54 & \\
\hline ME49 GRA14-6xHA & ME49 $\Delta k u 80$ & $\Delta k u 80 \Delta h x$ & & & $\mathrm{TR}^{1}$ & \\
\hline $\mathrm{M} \Delta \operatorname{gra} 14$ & ME49 $\Delta k u 80$ & $\Delta k u 80 \Delta h x$ & $H X$ & MPA + Xanthine & $\mathrm{TR}^{1}$ & \\
\hline
\end{tabular}

${ }^{1}$ This report 
bioRxiv preprint doi: https://doi.org/10.1101/2021.07.21.453261; this version posted July 21, 2021. The copyright holder for this preprint (which was not certified by peer review) is the author/funder, who has granted bioRxiv a license to display the preprint in perpetuity. It is made available under aCC-BY-NC 4.0 International license.

Table S4: Plasmids used in this manuscript

\begin{tabular}{|c|c|c|c|}
\hline Plasmids & Expression & Reference & Notes \\
\hline pmCherry-N1-VPS4A & $\begin{array}{l}\text { Vps4 wildtype } \\
\text { fused to mCherry }\end{array}$ & & \\
\hline pmCherry-N1-VPS4AEQ & $\begin{array}{l}\text { Vps4 dominant } \\
\text { negative fused to } \\
\text { mCherry }\end{array}$ & & \\
\hline pCMVNLGag-Venus & $\begin{array}{l}\text { HIV-1 Gag fused to } \\
\text { Venus }\end{array}$ & & \\
\hline pCMV-Rev & HIV-1 Rev & & \\
\hline pCMV-Vphu & HIV-1 Vphu gene & & \\
\hline $\mathrm{pCMVNLGag} \Delta p 6$ & $\begin{array}{l}\text { HIV }-1 \text { Gag with } \\
\text { deletion of the p6 } \\
\text { domain }\end{array}$ & $\mathrm{TR}^{1}$ & \\
\hline pCMVNLGagGRA14 & $\begin{array}{l}\text { HIV-1 Gag } \\
\text { expressing GRA14 } \\
\text { predicted late } \\
\text { domain motifs }\end{array}$ & $\mathrm{TR}^{1}$ & \\
\hline pCMVNLGagGRA14 ${ }^{\text {TSG101- }}$ & $\begin{array}{l}\text { PTAP-mutation in } \\
\text { the GagGRA14 }\end{array}$ & $\mathrm{TR}^{1}$ & $\begin{array}{l}\text { Substitution of the } \\
\text { PTAP motif to AAAA }\end{array}$ \\
\hline pCMVNLGagGRA14 ALIX- & $\begin{array}{l}\text { YPNL mutation in } \\
\text { the GagGRA14 }\end{array}$ & $\mathrm{TR}^{1}$ & $\begin{array}{l}\text { Substitution of the } \\
\text { YPNL motif to AAAA }\end{array}$ \\
\hline pCMVNLGagGRA14 ${ }^{\text {TSG101-ALIX- }}$ & $\begin{array}{l}\text { Mutations in both } \\
\text { of GagGRA14 late } \\
\text { domain motifs } \\
\text { (PTAP and YPNL) }\end{array}$ & $\mathrm{TR}^{1}$ & $\begin{array}{l}\text { Substitution of the } \\
\text { PTAP and YPNL motif } \\
\text { to AAAA and AAAA }\end{array}$ \\
\hline pYFP (pVenus) & $\begin{array}{l}\text { Fluorescence } \\
\text { reporter protein }\end{array}$ & & $\begin{array}{l}\text { Kindly provided by } \\
\text { John Boothroyd }\end{array}$ \\
\hline pTRE2-mCherry & $\begin{array}{l}\text { mCherry } \\
\text { expression under } \\
\text { the tetracycline- } \\
\text { inducible promoter }\end{array}$ & 3 & \\
\hline pTet-ON & $\begin{array}{l}\text { Reverse tet- } \\
\text { responsive } \\
\text { transcriptional } \\
\text { activator. }\end{array}$ & 3 & \\
\hline pGRA14-HA & $\begin{array}{l}\text { GRA14 tagged at } \\
\text { the C-terminus with } \\
\text { a single HA }\end{array}$ & 26 & $\begin{array}{l}\text { Kindly provided by } P \text {. } \\
\text { Bradley }\end{array}$ \\
\hline pGRA14-HA ${ }^{W T} \_C A T$ & $\begin{array}{l}\text { Introduction of a } \\
\text { CAT selectable } \\
\text { marker in the } \\
\text { pGRA14-HA }\end{array}$ & $\mathrm{TR}^{1}$ & \\
\hline pGRA14-HA ${ }^{\text {TSG101-_CAT }}$ & $\begin{array}{l}\text { GRA14 encoding } \\
\text { mutation in the } \\
\text { PTAP motif }\end{array}$ & $\mathrm{TR}^{1}$ & $\begin{array}{l}\text { Substitution of the } \\
\text { PTAP motif to AAAA }\end{array}$ \\
\hline
\end{tabular}

${ }^{1}$ This report 
bioRxiv preprint doi: https://doi.org/10.1101/2021.07.21.453261; this version posted July 21, 2021. The copyright holder for this preprint (which was not certified by peer review) is the author/funder, who has granted bioRxiv a license to display the preprint in perpetuity. It is made available under aCC-BY-NC 4.0 International license.

Table S5: Antibodies used in this study

\begin{tabular}{|c|c|c|c|}
\hline Antibodies & $\begin{array}{l}\text { Dilution for } \\
\text { Immunofluorescence }\end{array}$ & $\begin{array}{l}\text { Dilution for } \\
\text { Immunoblot }\end{array}$ & Source \\
\hline Mouse aTSG101 & & $1: 200$ & $\begin{array}{l}\text { Santa Cruz, Cat\# sc- } \\
7964\end{array}$ \\
\hline Mouse $\alpha A$ LIX & $1: 100$ & & $\begin{array}{l}\text { BioRad, Cat\# } \\
\text { MCA2493 }\end{array}$ \\
\hline Rabbit aCHMP4B & & & $\begin{array}{l}\text { Proteintech, Cat\# } \\
\text { 13683-1-AP }\end{array}$ \\
\hline Mouse aCHMP4A & $1: 100$ & & $\begin{array}{l}\text { Santa Cruz, Cat\# sc- } \\
514869\end{array}$ \\
\hline Rabbit aPDCD6 & & $1: 2000$ & $\begin{array}{l}\text { Proteintech, Cat\# } \\
\text { 12303-1-AP }\end{array}$ \\
\hline Rabbit aPEF1 & & $1: 4000$ & $\begin{array}{l}\text { Proteintech, Cat\# } \\
\text { 10151-1-AP }\end{array}$ \\
\hline Mouse aMAPK7 & $1: 250$ & & $\begin{array}{l}\text { Origene, Cat\# } \\
\text { TA502148 }\end{array}$ \\
\hline Rabbit $\alpha \mathrm{HA}$ & $1: 800$ & $1: 5000$ & CST, Cat\# 3724S \\
\hline Rat $\alpha \mathrm{HA}$ & $1: 800$ & & $\begin{array}{l}\text { Millipore Sigma, Cat\# } \\
118674230001\end{array}$ \\
\hline Mouse $\alpha H A$ & $1: 800$ & & $\begin{array}{l}\text { BioLegend, Cat\# } \\
901533\end{array}$ \\
\hline Rabbit aGRA14 & $1: 500$ & $1: 10000$ & $\begin{array}{l}\text { Kindly provided by Y. } \\
\text { Nishikawa }\end{array}$ \\
\hline Mouse aGRA8 & $1: 500$ & $1: 5000$ & $\begin{array}{l}\text { Kindly provided by G. } \\
\text { Ward }\end{array}$ \\
\hline Mouse aGRA1 & $1: 1000$ & $1: 10000$ & $\begin{array}{l}\text { Kindly provided by } \mathrm{F} \text {. } \\
\text { Spano }\end{array}$ \\
\hline Rabbit $\alpha$ GRA1 & $1: 2000$ & & \\
\hline Mouse aMAG1 & & $1: 2000$ & \\
\hline Rabbit aGRA4 & & $1: 20000$ & $\begin{array}{l}\text { Kindly provided by L. } \\
\text { D. Sibley }\end{array}$ \\
\hline Rabbit aGRA6 & & $1: 15000$ & $\begin{array}{l}\text { Kindly provided by L. } \\
\text { D. Sibley }\end{array}$ \\
\hline Mouse aGRA7 & $1: 1000$ & & $\begin{array}{l}\text { Kindly provided by } P \text {. } \\
\text { Bradley }\end{array}$ \\
\hline Rabbit aGAP45 & $1: 1000$ & & $\begin{array}{l}\text { Kindly provided by D. } \\
\text { Soldati }\end{array}$ \\
\hline Rabbit aGFP & $1: 200$ & & $\begin{array}{l}\text { Thermo Fisher } \\
\text { Scientific, A-11122 }\end{array}$ \\
\hline Rabbit aTub & & $1: 2000$ & $\begin{array}{l}\text { Proteintech, Cat\# } \\
\text { 10068-1-AP }\end{array}$ \\
\hline Human aGag & & $1: 2000$ & \\
\hline
\end{tabular}

${ }^{1}$ This report 
Table S6: Primers used in this manuscript

\begin{tabular}{|c|c|c|}
\hline & Pirmer & Sequence \\
\hline P1 & FWR Gaglnsert.664-1456 & $\begin{array}{l}\text { CAGAAGGAGCCACCCCACAAGATTTAAATACCATGCT } \\
\text { AAACACAGTGGGG }\end{array}$ \\
\hline $\mathrm{P} 2$ & RVS GagInsert.664-1456 & $\begin{array}{l}\text { TTCCACCACCACCACCGGAAATCCCAAAATTCCCTGG } \\
\text { CCTTCCCTTGTGG }\end{array}$ \\
\hline P3 & TgGRA14-Cterm.F & ACGCCTCGTGTGCGCGCTTTTC \\
\hline P4 & TgGRA14-Cterm.R & TTCGCTTGGTCTCTGGTAGCCC \\
\hline P5 & RVS Gaglnsert-GRA14Cterm.2 & $\begin{array}{l}\text { CСTCTTCTCCAAAGTCTCCACTGTCAAAATTCCCTGGC } \\
\text { CTTCCСTTGTGG }\end{array}$ \\
\hline P6 & $\begin{array}{l}\text { FWR } \\
\text { GRA14Cterm.2Insert.1457-1759 }\end{array}$ & $\begin{array}{l}\text { CCACAAGGGAAGGCCAGGGAATTTTGACAGTGGAGA } \\
\text { CTTTGGAGAAGAGG }\end{array}$ \\
\hline P7 & $\begin{array}{l}\text { RVS GRA14Ctermlnsert.1457- } \\
1759\end{array}$ & $\begin{array}{l}\text { TTCCACCACCACCACCGGAAATCCCTTCGCTTGGTCT } \\
\text { CTGGTAGCCCAGC }\end{array}$ \\
\hline P8 & GagGRA14seq.1541.fwr & TACGTTCCGCCCATGTATCC \\
\hline P9 & GRA14-HA.F & GGGGCATAAGAATGCTACAATC \\
\hline P10 & HA.R & CGGGGACGTCGTACGGGTAGGC \\
\hline P11 & ALIXmut.Q5.F & gctgcaCACAGGCTGGGCTACCAG \\
\hline $\mathrm{P} 12$ & ALIXmut.Q5.R & cgcagcTAGCATAGACGCAGGGGC \\
\hline P13 & Q5.TSG101mut2.fwr & getgctCCCGCCCCTGCGTCTATG \\
\hline P14 & Q5.TSG101mut2.rvs & agcggcTTGTACTCGATAACCTCCATGAGACG \\
\hline P15 & MAN343 & $\begin{array}{l}\text { GTCCGTTACCCATGTTGCTGTACCAGTGGTGTTTTTG } \\
\text { CGTCGGGTATAATAGCCATTTAATGGCGCCGTATATTT } \\
\text { TTCAC }\end{array}$ \\
\hline P16 & MAN344 & $\begin{array}{l}\text { GTGAAAAATATACGGCGCCATTAAATGGCTATTATACC } \\
\text { CGACGCAAAAACACCACTGGTACAG } \\
\text { CAACATGGGTAACGGAC }\end{array}$ \\
\hline $\mathrm{P} 17$ & MAN345 & GCACGGACCATCCGAGGACACTACAG \\
\hline P18 & MAN346 & GACAAGCGAAATGGTACGAAGCGGGAC \\
\hline P19 & MAN347 & GGTGGATTGGTCAAGGACAGAGTTGAG \\
\hline P20 & MAN348 & GAAGTCGCGGAACATCTCGTTGAAGTC \\
\hline
\end{tabular}

